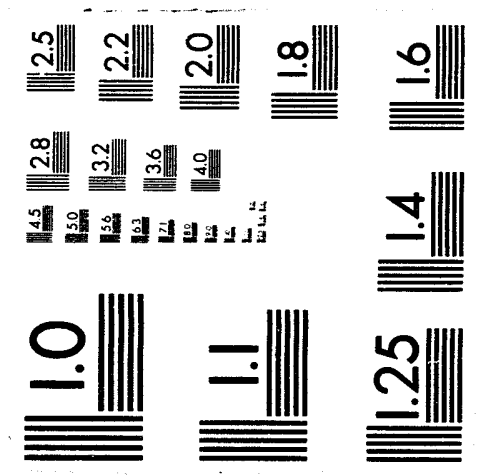





\section{NONDESTRUCTIVE X-RAY MICROANALYSIS BIDIRECTIONAL SCANNING AND DATA ACQUISITION SYSTEM}

R. L. Lawson

Development Division managed by

MARTIN MARIETTA ENERGY SYSTEMS, INC.,

for the

U.S. DEPARTMENT OF ENERGY

under contract DE-ACO5-84OR2 1400

6.

MARTIN MARIETTA ENERGY SYSTEMS, INC.

FOR THE UNITED STATES

DEPARTMENT OF ENERGY

DIGTRIBUTION OF THIS DOCUMENT IS UNLMMITED

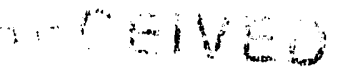




\section{DISCLAIMER}

This report was prepared as an account of work sponsored by an agency of the United States Government. Neither the United States Government nor any agency there of, nor any of their employees, makes any warranty, express or implied, or assumes any legal liability or responsibility for the accuracy, completeness, or usefulness of any information, apparatus, product, or process disclosed, or represents that its use would not infringe privately owned rights. Reference herein to any specific commercial product, process, or service by trade name, trademark, manufacturer, or otherwise, does not necessarily constitute or imply its endorsement, recommendation, or favoring by the United States Government or any agency thereof. The views and opinions of authors expressed herein do not necessarily state or reflect those of the United States Government or any agency thereof. 


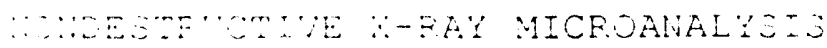

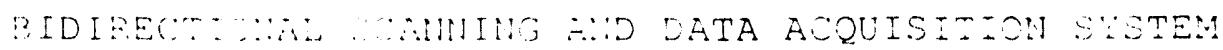

R.L. LAWSON

$9: 12: 89$ 


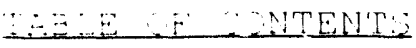

:.2500UC.2. . . . . . . . . . . . . . . . . . . . . . . . . 3

IอETOUS :UTEMS . . . . . . . . . . . . . . . . . . . . . . 3

OYERALL CEE . . . . . . . . . . . . . . . . . . . . . . . .

UETEM HREDWARE . . . . . . . . . . . . . . . . . . . . . . 3

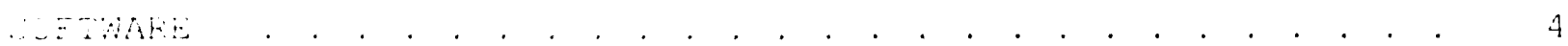

EUMGIONAL DESCEIPTIZ:. . . . . . . . . . . . . . . . . 4

BIDIEECTIONAL SCAN CEESET . . . . . . . . . . . . . . . . . 6

USIIS THE SOETWARE . . . . . . . . . . . . . . . . . . 7

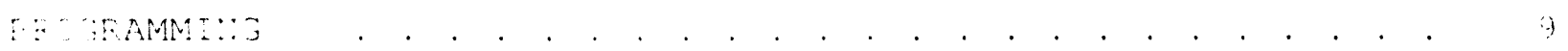

Y ILE JESCRIPTIONS . . . . . . . . . . . . . . . . . . . 9

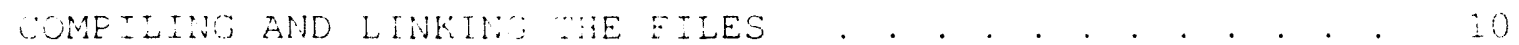

EROGEAMMING/HARDWARE E ECULIARITY . . . . . . . . . . . 10

DETAIZED FUNCTIONAL EESCRIPTION . . . . . . . . . . . . . . . 11

MEAI:IG OF ERROR ElaG TALUES . . . . . . . . . . . . . 24

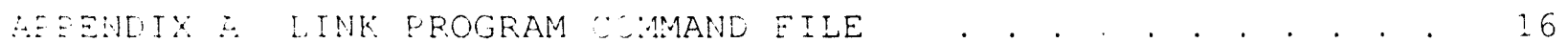

FILENAME: BESCAN LN: . . . . . . . . . . . . . . . . . 16

AEEENDIX E DOFTWARE FIOW ETAGRAMS . . . . . . . . . . . . . . . . 17

FEE EMLIX $\because$ MAIN PROGRAM F:: SUBROUTINE EILES . . . . . . . . $\quad 23$

EILEI:AME: BESCAN.FOF . . . . . . . . . . . . . . . . . 23

FILEMAME： CLEAR.FOR . . . . . . . . . . . . . . . . . 90

FILEVIAME : EISR.MAC . . . . . . . . . . . . . . . . . . 31

FIEE:ZAME: GETBDSEOE . . . . . . . . . . . . . . . . . 49

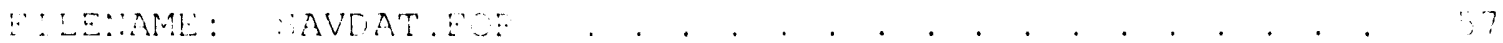

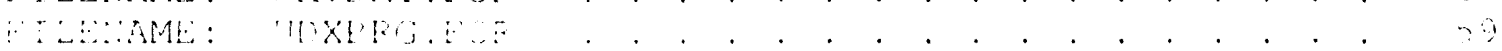

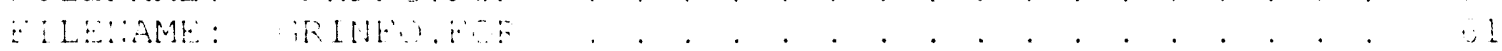

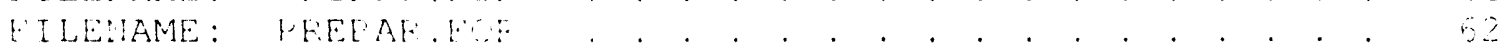

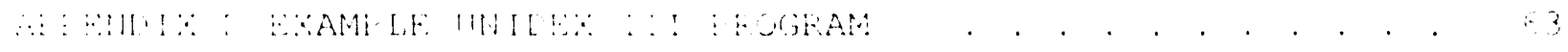




\section{INTRODUCTION}

A system for making fast scans of specimens and acquiring data was developed at the Jak Ridge Y-12 plant. An LSI 11/23 computer using the RT11 operating system controls the scan and data acquisition. Scan software was written which would program a Unidex II I stepping motor controller to make the scan motions while the position was monitored and the data acquired through the computer's timer/counter boards from the multichannel analyzer's four region of interest ( ROI) outputs. Small areas of a part or specimen are scanned by moving the part back and forth in the $x-$ ray beam using stepping motor actuated tables. A detector receives the scattered $x$-rays from the part and sends a signal to the multichannel analyzer which digitizes it. After the data has been acquired using the scan computer, the data is then transferred to a PC to where it is processed and an image is generated and dispiayed for analysis.

\section{PREVIQUS SYSTEMS}

This scanning and data acquisition system resulted after several previous attempts to acquire the complete spectrum data at high rates through the multichannel analyzer failed. Software generated for the previous system configurations included code to communicate with the multichannel analyzer through its serial interface, its bus interface (GPIB), and the programs to get the data and store it in a data file.

\section{OVERALL USE}

This data acquisition system is part of a larger system which is used for non-destructive $x$-ray microanalysis of parts. The image generated on the PC from the scan data is used tor studying part abnormalities. With four regions of interest, the distributions of four chemical elem.nts in a part can be imaged. This information can be used to determine the composition of unusual features on a part which may cause part failure.

\section{SYSTEM HARDWARE}

The sistem hardware consists of an $x$-ray machine, $x$-ray detector, translation tables, a multichannel analyzer, stepping motor controllers, and an LSI $11 / 23$ computer. The $x$-ray detector foeds the multichannel analyzer indirectly through other conditioning devices. The computer has five timericounter boards installed in it. One board uses the stepping pulses to control the other four counter boards which count the data pulses from the four region of interest outputs of the multichannel analyzer. An internal 
connection was made in the Unidex ill stepping motor controller to output the stepoing pulses to the counter board for position tracking and daza acquisition by the computer.

\section{SOETWARE EUNCTIONAL DESCRIPTION}

The following functional description of the scan program can best be understood using the block diagram of figure 1. First, an example scan setup is given as:

NURBER OF X POINTS $=100$

$X$ POINT SIZE ( MICRONS ) $=10.0$

TIME per X POINI ( SECONDS ) $=0.1$

NUMBER OF Y POIINS $=100$

$Y$ MOVE ( MICRONS ) $=10.0$

TIME per Y MOVE ( SECONDS ) $=.1$

NUMBER OF ROIS $=4$

SPECIMEN SCAN QUADRANT $=4$

Using this information, the computer will calculate the number of steps and the feedrate to perform the scan. The NUMBER OF X POINTS is the number of data points to collect for one scan of the $x$ axis. The $X$ POINT SIZE is the distance over which counts are taken for each data point. Therefore, the total distance in microns covered along the $x$ axis will be equal to the NUMBER OF $X$ POINTS multiplied by the $x$ POINT SIZE. Since the Unidex iii moves the specimen 1 micron per step, this number is equal to the number of steps required to scan the $x$ axis. For this example, the total number of steps is 1000 and the feedrate is 100 steps per second. since the step counter board's overflow output triggers the ROI counters, an extra step must be added to the total \# of steps. Eor this exampie, the total number of steps to scan the $x$ axis would be 1001 . With the scan program now defined, the LSI $11 / 23$ computer will load it into the unidex. III stepping motor controller through the GPIB interface. After loading the scan program, the step Counter ST2 interrupt routine will be enabled, then the unidex scan program will be started. When the unide: starts its scan program, it will send a beginning of $\because$ axis scan pulse which will cause the step counter to start counting the stepping motor pulses. The first stepping motor pulse will cause a counter overflow which will start the ROI counter boards runnina. After this Eirst overfiow, the step counter will only overflow on every loth pulse for this example. Each time an overflow occurs, the roI counter boards will save their present count in a buffer, cero their counter, and start counting again. The computer will detect the step counter overflow and will read the ROI counter buffers while the boards are counting. The computer stores the count data 


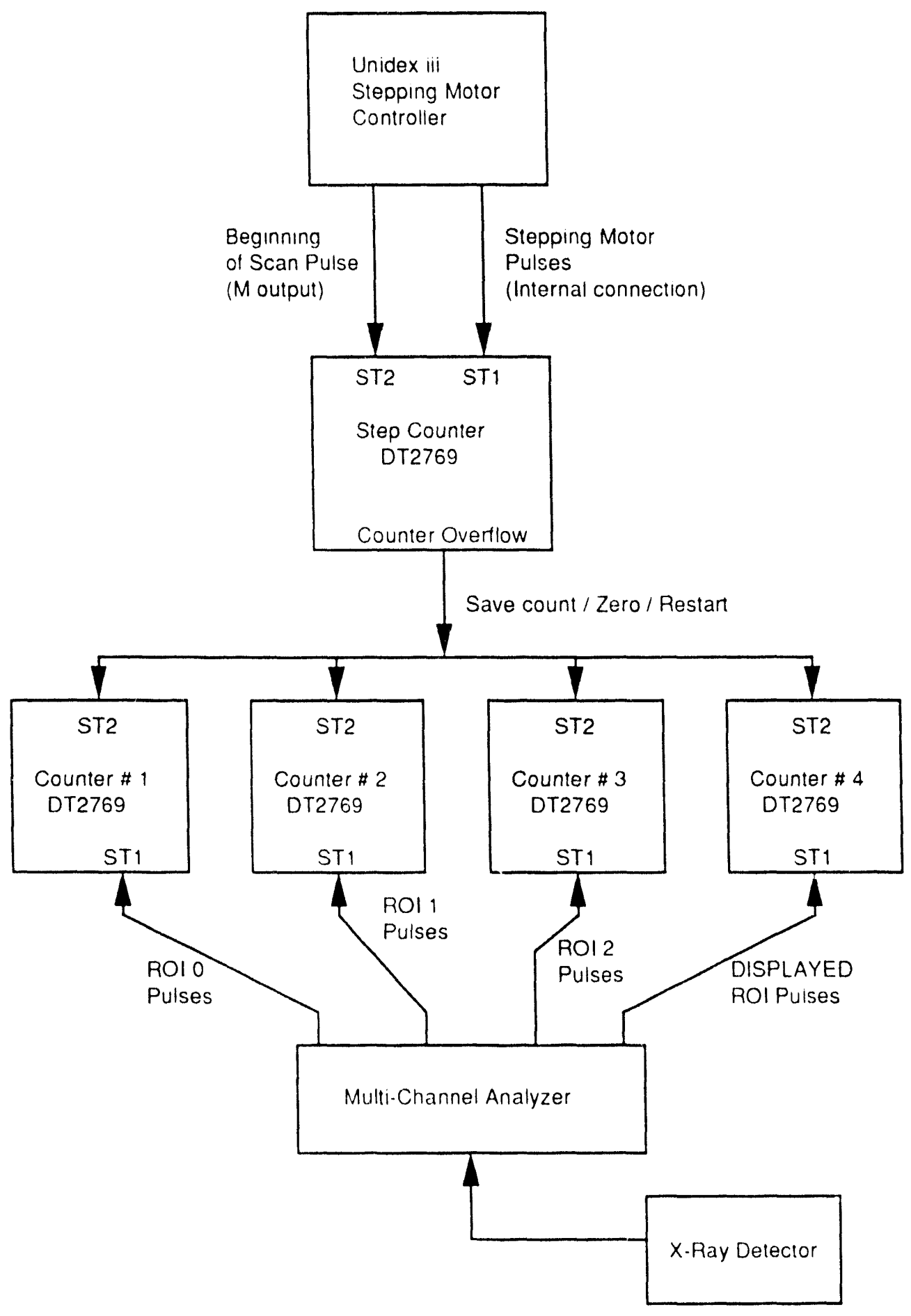

Figure 1

Scan Hardware Block Diagram 
:or wah RoI in memory. Wher zre scan is complete, the computer $\because$ : $\because t$ he data com memor: and save it in the specified data $\therefore \therefore \cdots$

OLISECTIONAL SCAN OFESET

A reslit of using a steppina pulse to start/reset the ROI counters is as. offset in the scan data. The reverse scanned data offset is unknown but could be as much as 1 micron ( 1 step) or 0.1 micron iE the microstepper is used. Figure 2 is a scan example that demonstrates the offset.

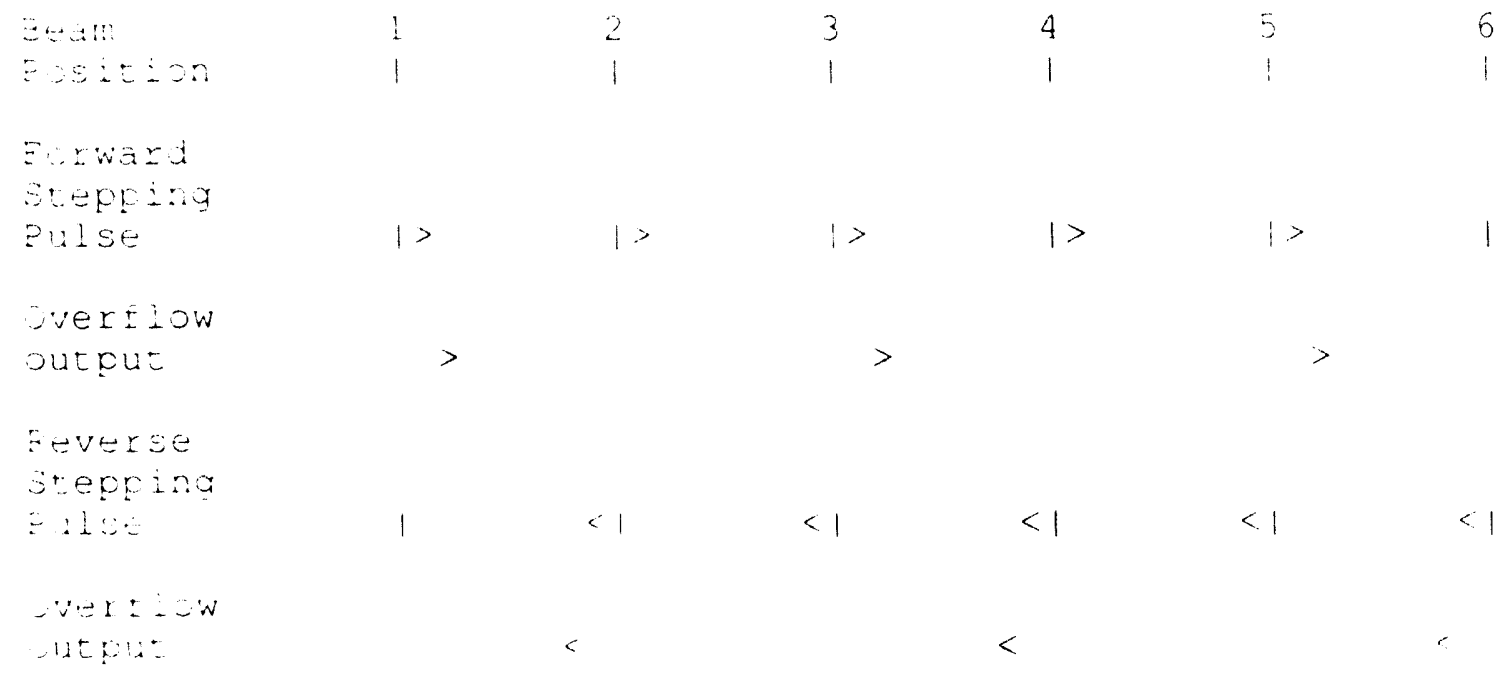

Eigure?

This example is for a scan that would acquire 2 data points of 2 aicron widths for each $\because$ axis scan. Now consider the tirst lata sin. rat would be acquired. When the ROI counter boards receive r.: a rard overtlow pulee, hey will start counting. Although amburut, the forward overtaw pulse should occur before the

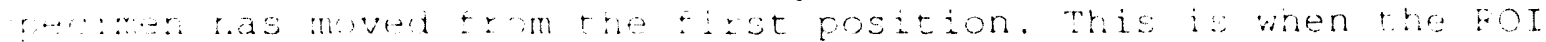

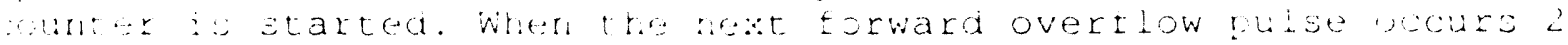

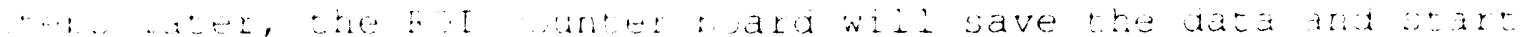

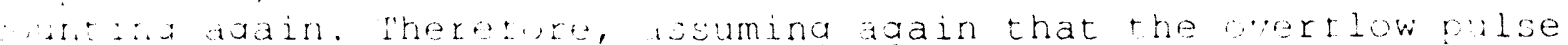

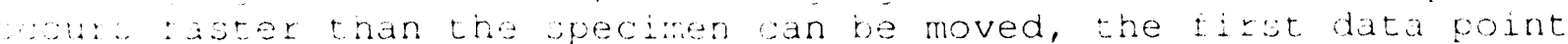
a. : : an average of the osnts for the area from posilion 1 to a. : : a. a The second tata jont will be read from the couner sara wen the third torwa vertow oulse occurs. ( The

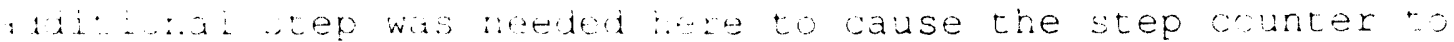

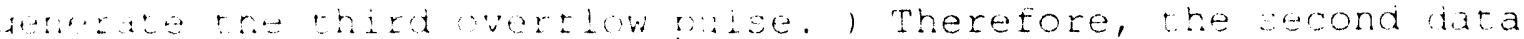

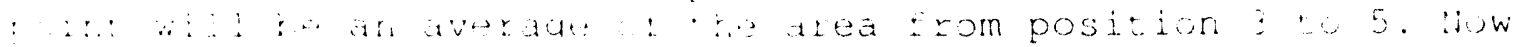


consider the reverse scan. The beam starts at position 6 on the specimen. When the first step occurs, an overflow pulse will be generated to start the ROI counters. Two steps later, another overflow pulse will occur to save the ROI counts and restart counting. Still assuming that the counters are started before the specimen is moved, the third data point will be an average over the area from 6 to 4 and the fourth data point will be an average of the area from positions 4 to 2 . Since most of the features imaged by this system are several microns in size and most data points consist of an average of 5 to 10 microns, a 1 micron offset between the forward and reverse scan data should not present a problem.

The sequence described above is the worst case. The best case would be to assume that the stepping motors move the specimen very quickly and spend most of their time sitting in one of the positions represented in figure 2. If this were the case, then an average of the counts for positions 2 and 3 would represent the first data point, 4 and 5 for the second data point, 5 and 4 for the third data point, and 3 and 2 for the forth data point. In this case the offset between the forward and reverse scans would be zero microns. Slow scans will approach the best case and fast scans will approach the worst case. Since the stepping motors can move the specimen at about 400 steps per second without the speed being ramped up, then a slow scan could be any scan which moves the specimen at 100 steps per second or less. Although the offset caused by the data acquisition system is present in the data, other elements such as the beam width and backlash must also be considered to determine the overall affect on the data.

\section{USING THE SOFTWARE}

To start the bidirectional scan program, the command 'RUN BESCAil' must be entered at the system prompt. When the scan program is started, a main menu is displayed.

Main Menu

0. STOP

1. Bidirectional Scan

2. Retrieve data from Memory

Enter \# of Choice >

The option to retrieve the data from memory is needed only when the scan program crashes. Most crashes occur after the data has 
been acquired and when the computer attempts to put the data in a disk file. These zrashes are usually due to insufficient space on the disk to put the data. When this happ ns, the user can free up space on the data jisk by either squeezing the free space or deleting some old data files. When the space is available for storing the data, =he scan program can be recun and the retrieve option selected to save the data to a file.

The scan option pulls up another menu to allow the user to select the method of inputting the scan setup data.

SCAN MENU

0. Main Menu

1. Eile Input

2. Manual Input

ENTER \# OF CHOICE ? >

When the file input option is selected, the program will request a setup filename. The setup information will be read from file and displayed for the user to verify that setup information is correct. If the user accepts the setup, then the program wili continue by requesting a data file name. Upon entering the file name, the user will be asked to verify that the unidex III and the multichannel analyzer are ready. After confirming the ready status of the instruments, the program will prepare and load the scan program into the unidex III stepping motor controller. When the computer is ready, it will prompt the usec to press the return key to start the scan. While the interrupt routines are handling the data acquisition, the main program will display the bidirectional scans progress. The scan position is correct for the forward scans but is inverted for the reverse scans. At the end of the scan, the computer will get the data from memory and store it in the specified data file.

If the manual input option was selected, then the user must enter the scan setup irformation. The following information will be required.

NUMBER OF $X$ POINTS

$X$ POINT SIZE ( MICRONS )

TIME per X POINT ( SECONDS)

NUMBER OF Y POINIS

$Y$ MOVE ( MICRONS)

TIME per Y MOVE ( SECONDS ) 
NUMBER OF ROIS

SPECIMEN SCAN QUADRANT

The NUMBER OF $X$ POINTS is the number of data points that the user wants to collect. The $X$ POINT SIZE (MICRONS) is the area over which the count data will be taken. The total scan length will be the NUMBER OF $x$ POINTS multiplied by the $x$ POINT SIZE. The TIME per $X$ POINT (SECONDS) is the amount of time orer which the count data will be acquired for each data point. The total scan time in seconds for one line along the $x$ axis will then be approximately equal to the NUMBER OF $x$ POINTS multiplied by the TIME per $X$ POINT. The NUMBER OF $Y$ POINTS is the number of $z$ axis scan 1 ines. The TIME per $Y$ MOVE is the amount of time the unidex will take to move the specimen to the next $x$ axis scan position. The NUMBER OF ROIs refers to the number of multichannel anal zer PoI outputs for which data will be collected. The SPECIMEN SCA: QUADRANT provides the $x$ and $y$ axis scan direction information wich respect to the present beam location on the specimen.

After the user enters the required information, the program will calculate some additional scan information and ask the user if any changes need to be made. When the user accepts the setup

information, the program will ask the user if he wants it saved to a file. If saving the setup is selected, the program prompt the user for a filename and save the setup.

\section{RROGRAMMING}

\section{EILE DESCRIPTIONS}

The source files used to build the bidirectional scan program are BESCAN. LNK, BESCAN.FOR, EISR.MAC, CLEAR.FOR, GETBDS.EOR, GRINEO.FOR, PREPAR.FOR, SAVDAT.EOR, UDXPRG.FOR. The GPIB object files located in the system area are also linked to the scan program. A description of each file is given below.

BESCAN. LNK

This command file is used to link the main proaram and its subroutines. It is invoked by enterina QBESCAN.LNK at the RT11 System prompt.

BESCAN. FOR

This is the main program. It provides a main menu for the user to select stoppina the crogram, the bidirectional scan menu, or retrieving the last scan's data from memor $\because$. When the scan menu is selected, the user is given a choice of returning to the main menu, starting a scan from a setup file, or entering the setup manually to start a 
CLEAR.EOR

FISR . MAC

GETBDS.FOR

SAVDAT.EOR

UDXPRG . FOR

GRINEO.FOR

PREPAR.EOR

IBUP.OBJ

IBVDP.OBJ scan .

This subroutine clears the vt100 terminal screen.

This file contains the interrupt service routines and associated subroutines needed to setup the scan. The timer interrupt service routine handles the interrupts for the Unidex stepping pulses. It will generate an overflow pulse which will cause the 4 ROI counters to save their current count, clear their counter, and start counting for the next data point. The counter overflow interrupt ioutine is used to check for counter overflows. A counter overflow will occur when more than 65535 counts is accumulated in the specified sampling time. The interrupt initialization and the get data subroutines are also included in this file.

This subroutine gets the bidirectional scan setup data from either a file or the user depending on the user's choice from the scan menu.

This routine gets the scan data from memory and puts it in the data file specified by the user when the scan is started. To get the data from memory, this routine calls the initialize and the get point routines which are located in the FISR.MAC file.

This routine generates the scan program to be loaded into the Unidex. III stepping motor controllex. The main program actualiy loads the program in the Unidex III.

This routine is used to get the information needed to retrieve the scan data from memory when the retrieve option is selected from the main menu.

This routine asks the user to prepare the Unidex II and the multichannel analyzer for the scan.

These two files were created from the vendor supplied source files. They provide the GPIB commands which are used throughout the software.

\section{COMPILING AND LINKING THE FILES}

The source files consist of both Fortran and Macro types. To compile the Fortran source files, use the command "FORT Eilename" 
where filename is the name of one of the Fortran files. To compile the Macro files, use the command "MAC filename" where filename is the name of a Macro file. When all of the source files have been compiled, use the command file BFSCAN. LNK to link them. To invoke the link command file enter the command "@BFSCAN.LNK". The scan program should now be ready to run.

\section{PROGRAMMING/HARDWARE PECULIARITY}

The step counter board's ST2 interrupt routine sets up the timer board such that it generates an overflow interrupt on the first step and thereafter an interrupt is generated on every $N$ th step. Although the software should be more than fast enough to stop the counter and reset it to generate overflow interrupts every $N$ th step, this approach was used to avoid the possibility that a stepping pulse would be missed due to the speed of software execution. The code in the ST2 interrupt routine which sets up the step counter board is :

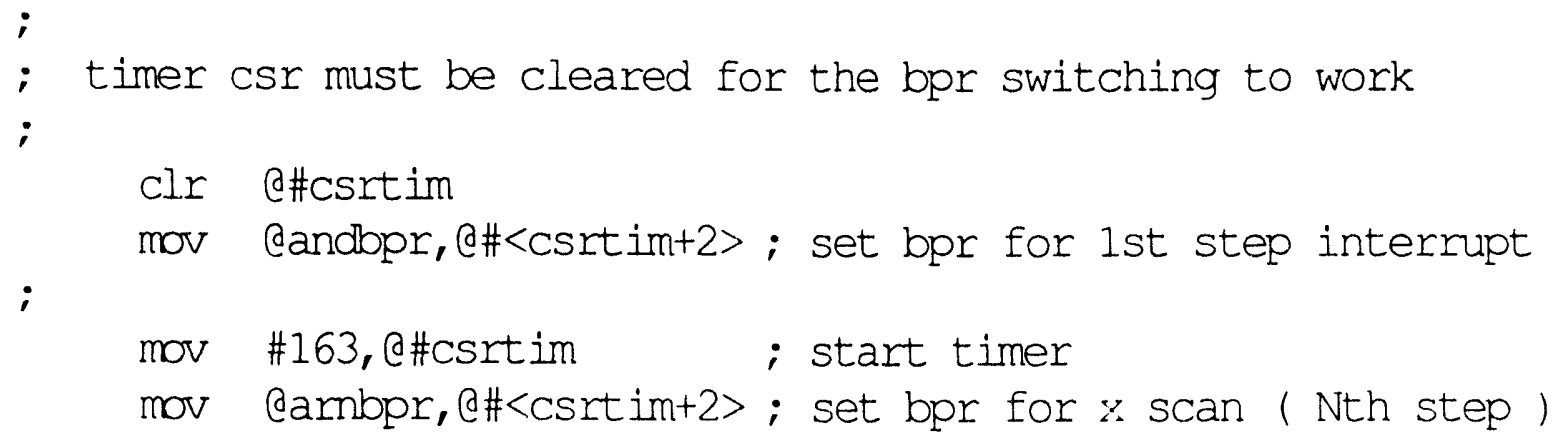

This code clears the timer's csr when the begging of scan pulse is received. The BPR register is then loaded with -1 to cause the counter board to generate an interrupt for the first step. After the counter board is started, the BPR register is loaded with the value to cause overflow interrupts every Nth stepping pulse. The counter board will use the initial BPR value for the first overflow interrupt. After the first overflow interrupt, the counter board will generate interrupts using the value of the BPR that was set after it was started.

DETAILED FUNCTIONAL DESCRIPTION

The following detailed functional description of the scan program and its interrupt routines is explained using the block diagram of figure 1, the flow diagrams in Appendix $B$, and the Unidex program in Appendix D. The following example scan setup will be used to 
allow for a step b: step description of the interrupt routines.

NUMBER OF X POINTS $=2$

$X$ POINT SIZE ( MICRONS ) $=2$

TIME per X POINT ( SECONDS ) $=0.1$

NUMBER OF Y POINTS $=2$

$Y$ MOVE ( MICRONS ) $=2.0$

TIME per Y MOVE ( SECONDS ) $=0.1$

NUMBER OF ROIS $=4$

SPECIMENJ SCAN QUACRANT $=4$

The computer will calculate the following irformation:

Total \# steps for $2 x$ axis $\operatorname{scan}=5$

$X$ axis Feedrate ( steps/sec) $=20$

\# steps per $x$ axis data point $=2$

$Y$ axis feedrate (steps/sec) $=20$

\# steps per y axis move $=2$

Using these calculated values, the computer will generate the Unidex program listed in Appendix $D$ with the appropriate values inserted. The scan program will be loaded into the Unidex III by the computer. After loading the scan program into the Unidex, the computer will enable the step counter's ST2 interrupt routine. When the user presses the return key, the computer will start the Unidex scan program running. As shown in the Appendix $B$ main program flow diagram, the main program stays in a loop displaying the scan status until the flag is set by the one of the interrupt routines. Now, lets outline the sequence of events starting with a look at the Unidex program is Appendix D.

Step 1 After the Unidex scan program loads the y points or $x$ axis line scan counter with the number 2, it will output a beginning of scan pulse. As shown in figure 1, this pulse is fed to the step counter board's ST2 input. When the step counter board detects the pulse, it will generate an interrupt causing the step counter's ST2 interrupt routine to execute.

Step 2 The step counter's ST2 interrupt routine ( see the step counter ST2 flow diagram in Appendix B, will then enable the step counter board's overflow interrupt while disabling the ST2 interrupts. The step counter board is setup slich that the first stepping pulse and then every other stepping pulse causes an overflow interrupt. Since a 200 millisecond delay is present in the unidex scan program, this step will occur before the scan program 
begins moving the specimen.

Step 3 After the scan program delay, the Unidex program will begin outputting pulses to move the specimen. As shown in figure 1 these stepping pulses are input to the step counter board. The first stepping pulse will cause the step counter board to generate an overflow pulse which will cause the ROI counter boards to start counting. The step counter overflow will also generate an interrupt causing the step counter overflow interrupt routine to execute.

Step 4 Since this was the first interrupt of the $x$ axis scan, the data from the ROI counter boards will not be saved by the step counter overflow interrupt routine.

Step 5 When the step counter board receives the next stepping pulse, it will not generate an overflow as explained in the Hardware Peculiarity section.

Step 6 The next stepping pulse causes the step counter board to generate an overflow pulse which will cause the ROI counter boards to save their present count, zero their counter, and restart counting the data pulses from the multichannel analyzer.

Step 7 The step counter board overflow also generates an interrupt causing execution of the step counter overflow routine. Since this was not the first overflow of the $x$ scan, the overflow routine will save the data for all 4 ROI counter boards in memory.

Step 8 The next stepping pulse is detected by the step counter board but does not cause an overflow for this example.

Step 9 The last stepping pulse of the $x$ scan is detected by the step counter board. The step counter board will output and overflow pulse to the ROI counter boards causing them to save their present count. (This is the reason for the additional $x$ scan step.)

Step 10 The step counter bocrd overflow also causes the overflow interrupt routine to be run. The step counter overflow interrupt routine will again get the count data from the ROI counter boards and save it in memory. The overflow routine also determines that this overflow was the end of the $x$ axis scan and disables itself while enabling the ST2 interrupt routine again.

Step 11 The step counter boards ST2 input has been enabled again and the Unidex program has completed the scan in the 
forward direction. The Unidex program wili now move the specimen up for the reverse scan along the $z$ axis. The delay during this move provides enough time for step 10 to be completed by the software.

Step 12 After completing the move to the next scan I ine, the Unidex scan program outputs the beginning of scan pulse and the procedure is repeated from step 1 .

Step 13 When the reverse direction scan is finished, the step counter overflow interrupt routine will again enable the ST2 interrupt routine. Since the ST2 interrupt routine checks for the end of the complete scan, the additional beginning of scan pulse output at the end of the Unidex scan program is required to cause the step counter ST2 interrupt routine to be executed.

Errors which can occur during the scan have not been discussed. Looking at the flow diagrams, there are several errors which can occur that are detected during a scan. The next section defines the meaning for each flag value.

MEANING OF ERROR FLAG VALUES

Flag values Meaning of flag value

Main program looping value while unidex program is scanning.

Set by step counter ST2 interrupt routine to indicate end of scan.

Set by step counter ST2 interrupt routine when an overrun error occurs. An overrun can ie caused by either an ST2 or an overflow overrun. since the Unidex pulses the step counter board's ST2 input at the end of the $x$ axis scans, the ST2 input could only cause the overrun error if noise or stray ST2 input pulses were occurring. The other cause of the overrun error is the overflow rate. If the step counter board is getting stepping pulses and generating overflows faster than the step counters overflow interrupt routine can handis, then an overrun error would occur. 
$-10$

$-11$

$-12$

$-13$

$-20$

$-21$

$-22$

$-23$

$-30$

$-40$

$-221$

$-222$

$-223$

$-224$

These values are set by the step counter's overflow interrupt routine. If either one of the 4 ROI counter board's ST2 flags are not serviced fast enough by the step counter overflow routine, then an overrun error will occur. The other cause of an overrun error would be the inability of the ROI counter overflow interrupt routine to quickly service the ROI counter board overflows. None of these errors are likely since the scan speeds are usually low as well as the data pulse rates.

These values are also set by the step counter's overflow interrupt service routine. These error values are used when one of the ROI counter boards does not have its ST2 flag set. Since the step counter board's overflow outpue is the ROI counter boards ST2 input, the most likely cause of this error would be a bad connection from the step counter board's overflow output.

Both of these values are set by the step counter overflow interrupt service routine. These values indicate an overrun of either the step counter's ST2 flag or its overflow flag. The causes are the same as error -210 .

These values are set by the ROI counters' overflow interrupt service routine. These are also overrun errors which would be caused by either the ST2 or the overflow bits. If the overrun error was caused by the ST2 bit, then the step counter's overflow interrupt service rout ine would be responsible. 
EILENAME： BESCAN.ILNK

R LINK

BESC $\because \mathrm{A}=\mathrm{BESC}=\mathrm{N} / 1$

SY': IEUP

SI: IBVDP

EISF

TIS-

CETES:O:

savciat/o: 1

1.dixpro:

urir:=o/o: 1

prepar/o:1

il 


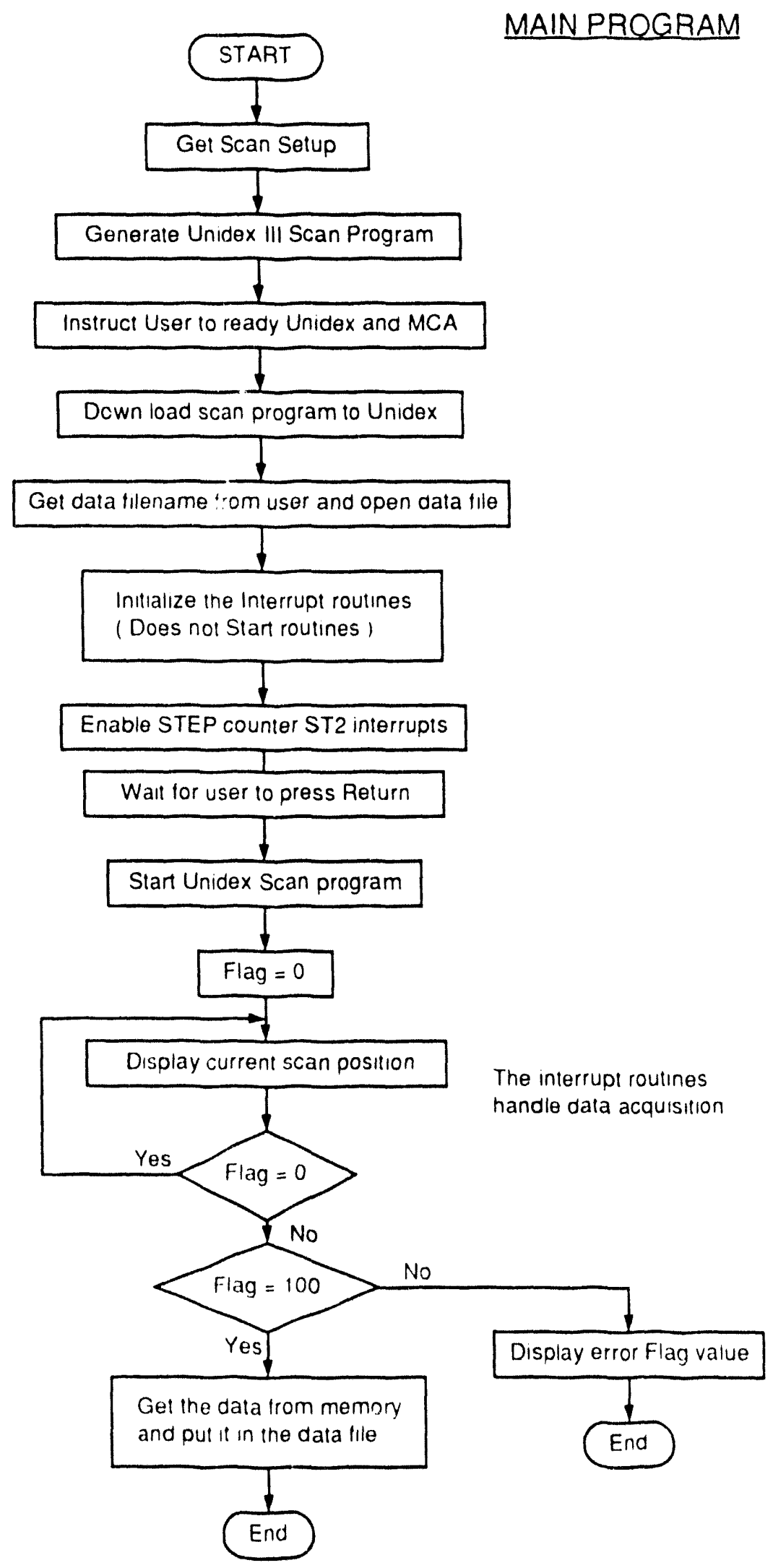




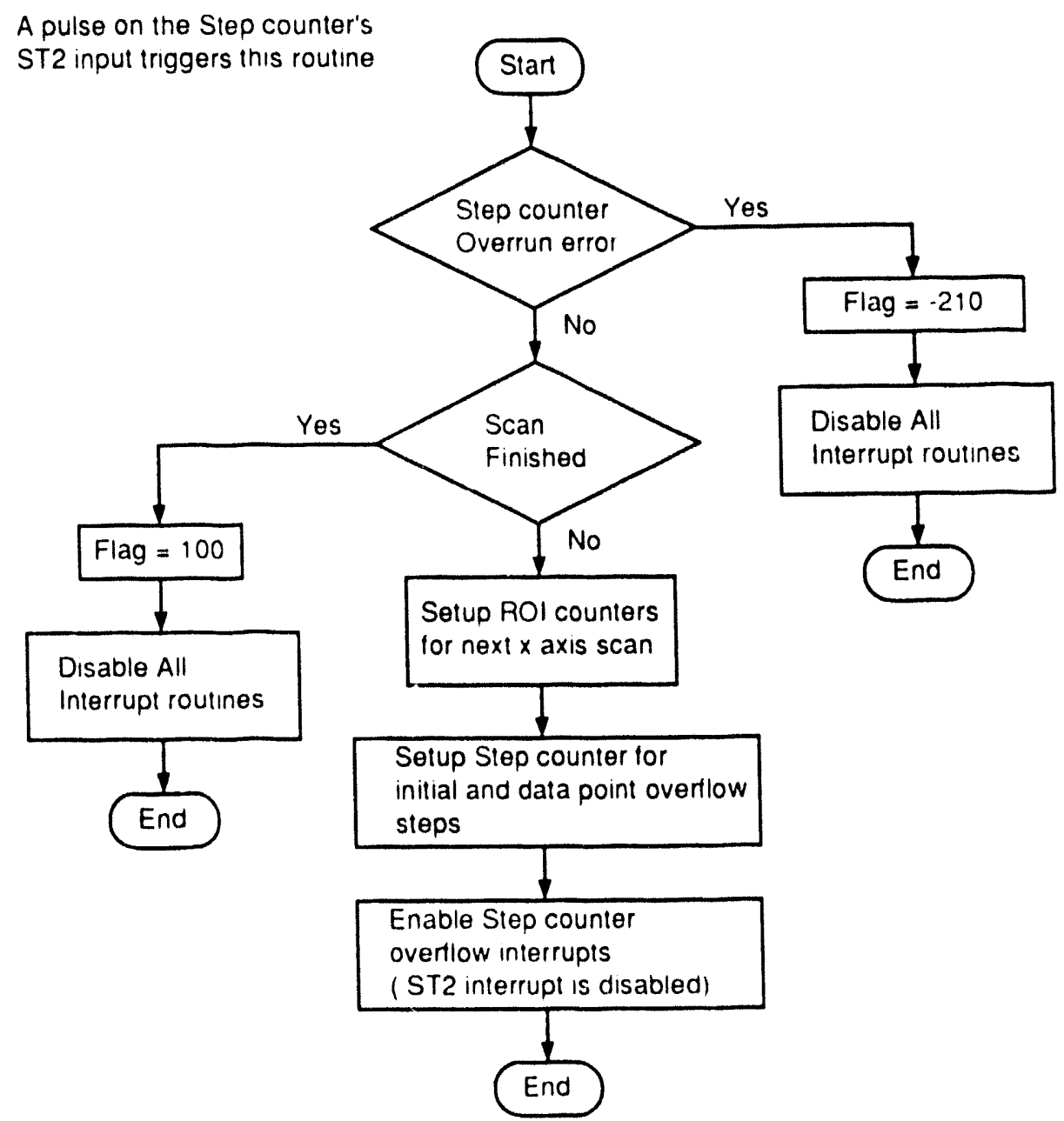


Step Counter Overflow Interrupt Routine

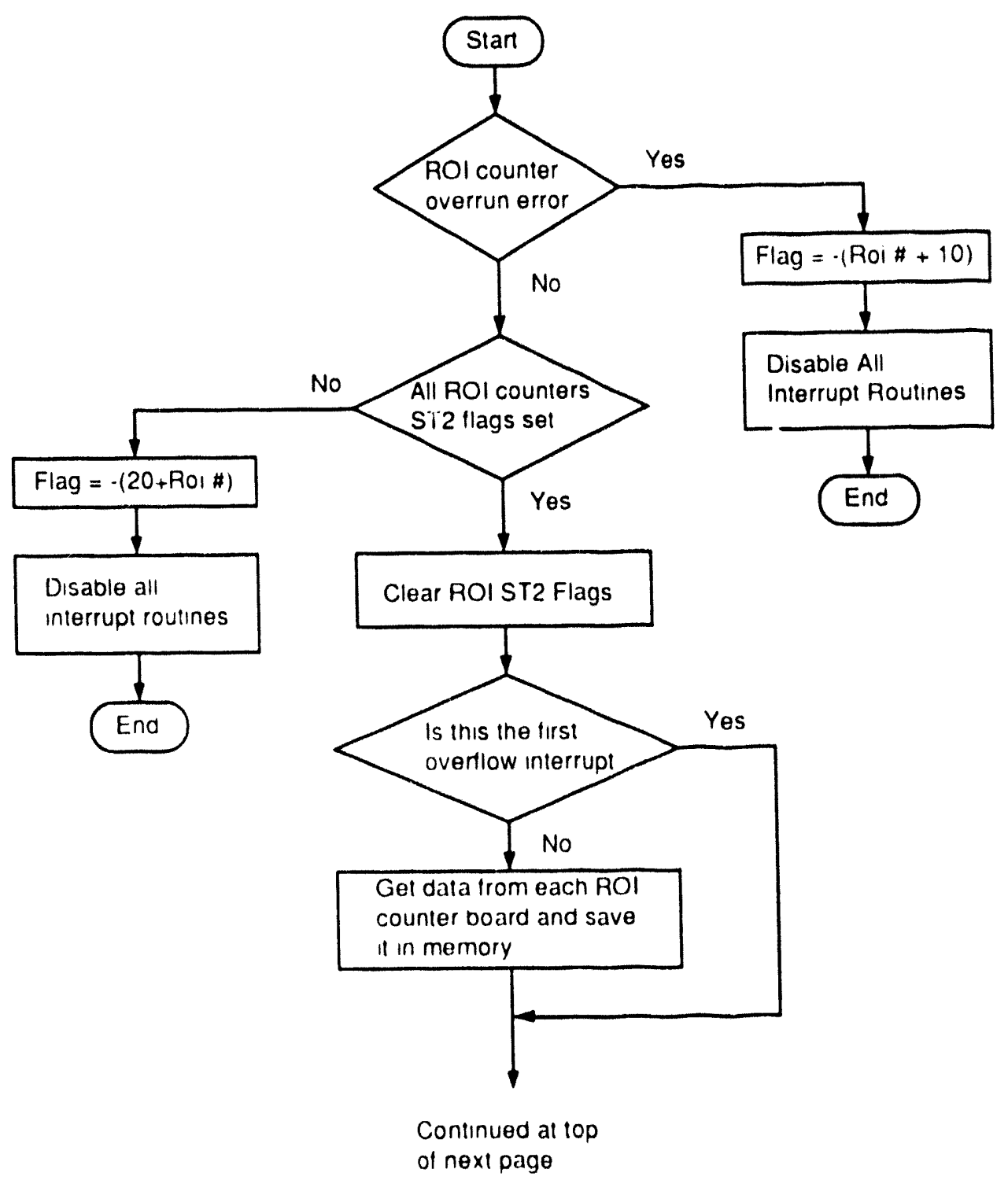




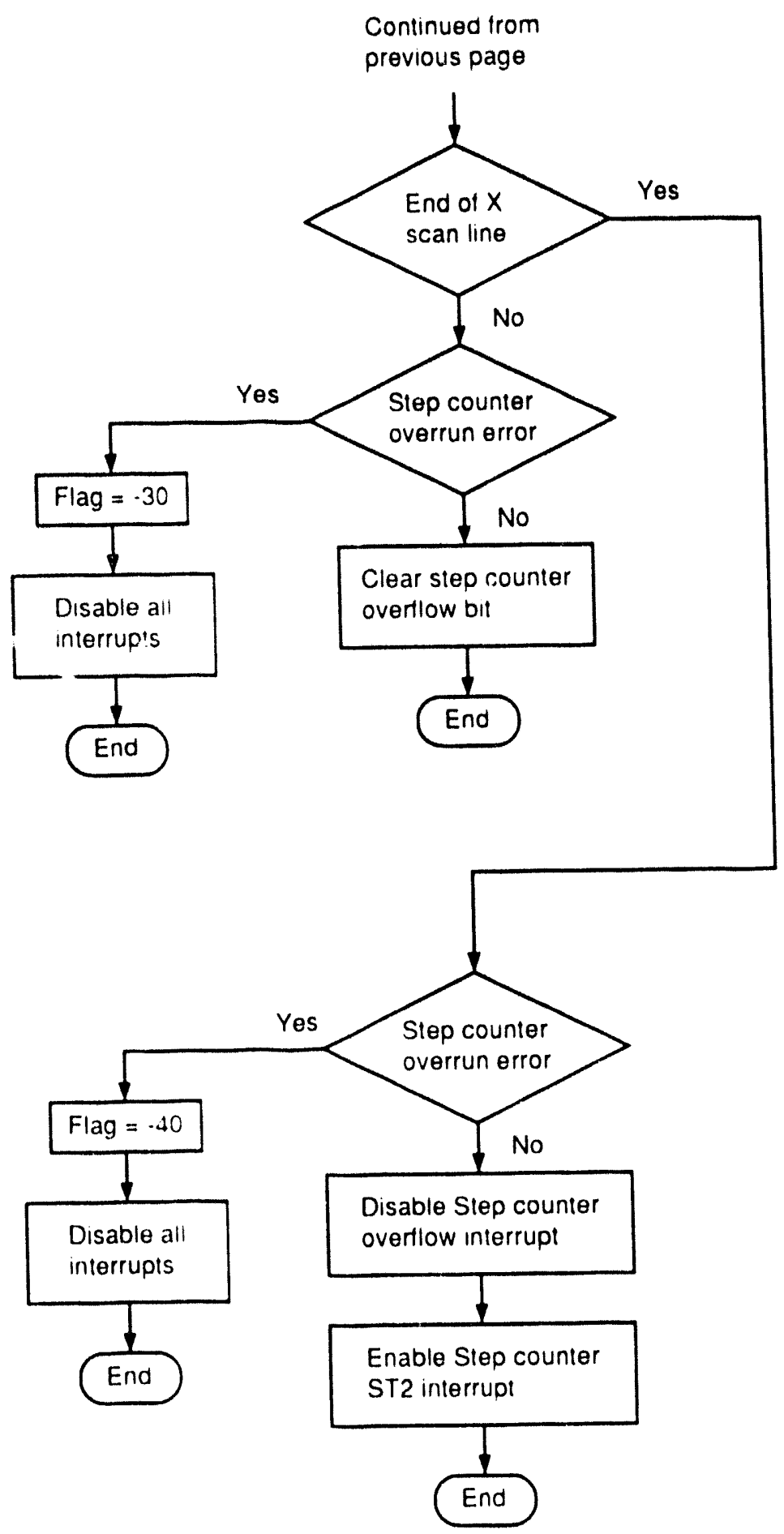


ROI Counter Overflow

Interrupt Routine

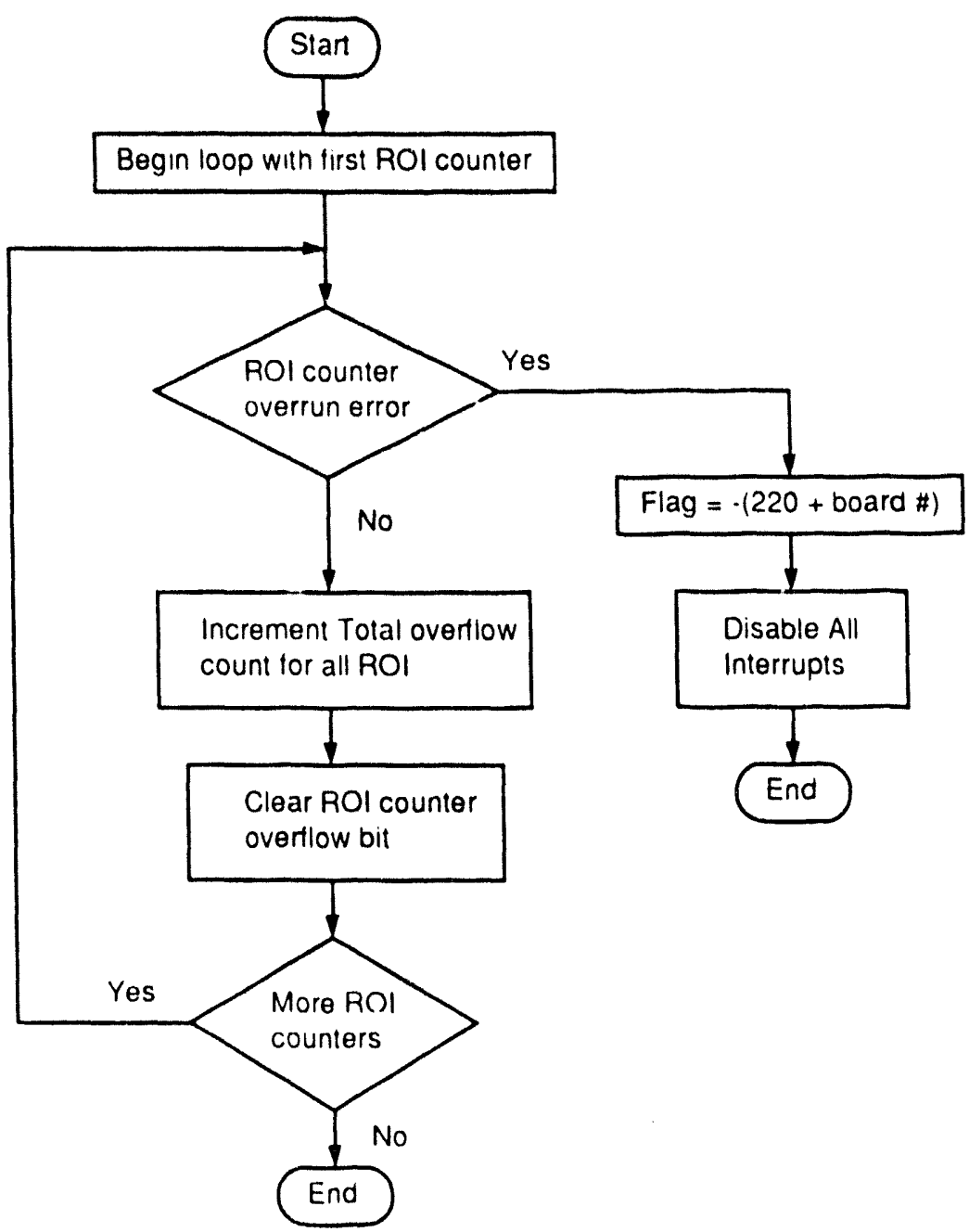




\section{APPENDIX C MAIN PROGRAM AND SUEROUTINE EIIES}

FILENAME: BESCAN.FOR

C

C. THIS PROGRAM IS USED TO PERFORM A EAST SCAN FOR THE $X$-RAY SYSTEM C

BYTE CMDSTG ( 6)

BYTE FIIENA ( 40$)$

BYTE UPROG ( 512 )

BYTE CR, LF, NIIL, eSC

C

INTEGER *2 IPVAL $(4), \operatorname{IRTC}(6)$

INTEGER*2 CSRTIM

INTEGER ${ }^{\star} 2$ CSRCNT

C

DATA CSRTIM / "170410 /

DATA CSRCNT / "170420 /

C

DATA IRTC / "170410, 0, "170420, 0, 0, 0 /

CALI DEVICE (IRTC)

C

$C R=" 15$

$L F=" 12$

NULI $=0$

esc $=27$

IEXST2=0 ! ELAG, NOT YET EXPECTING ST2 INTERRUPT

$\mathrm{IOECNT}=0$

C

CALI IPOKE (CSRTIM, 0) ! DISABLE TIMER

CALU IPOKE (CSRCNT, 0) ! DISABLE COUNTER

C

14 call clear

call mamenu ( iopt )

if ( iopt .eq. 0 ) stop

if ( iopt.eq. 1 ) goto 33

if ( iopt .eq. 2 ) goto 19 


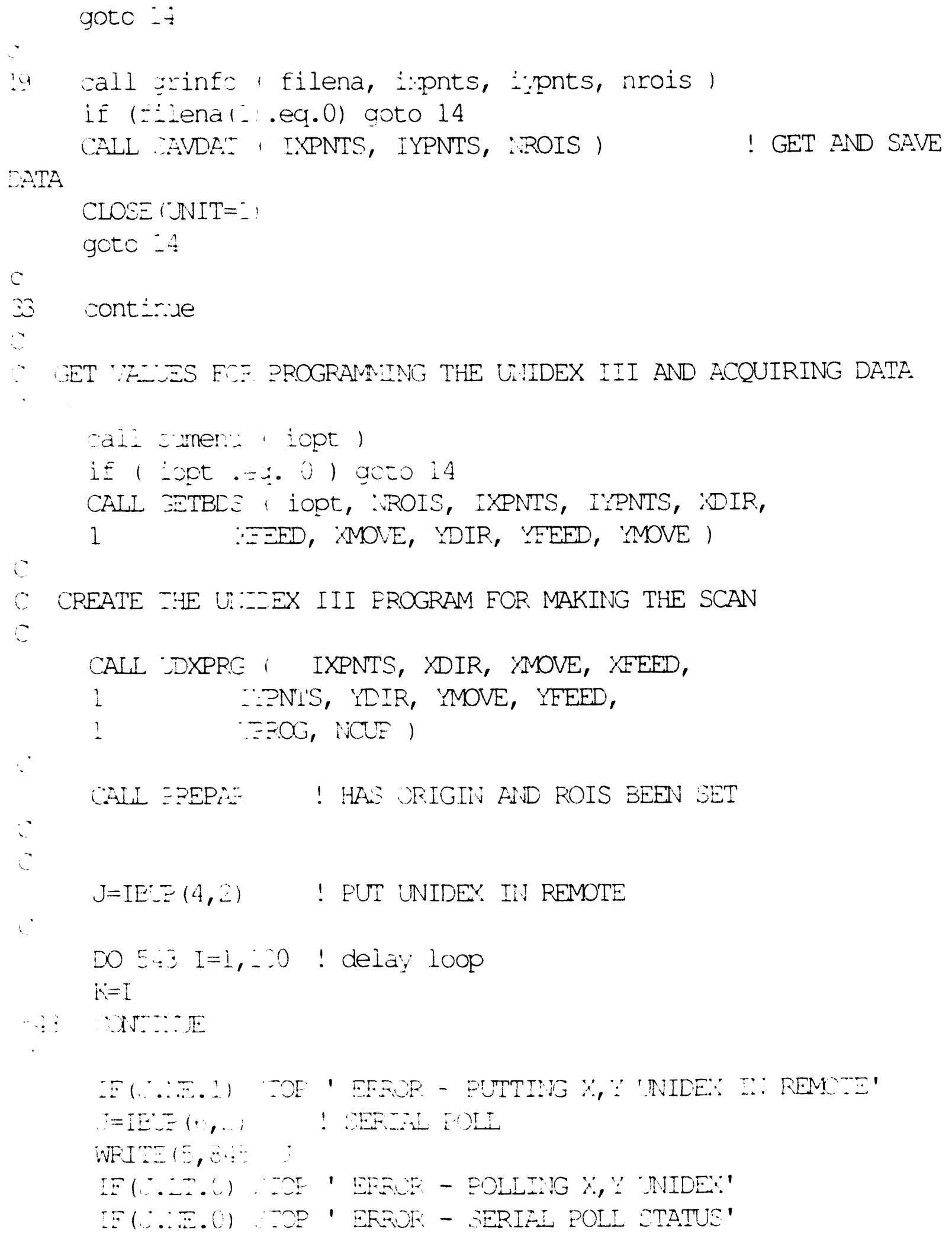


C.

C SEND PROGRAM TO UNIDEX III

C

IDVCE $=2$ ! DEVICE \# OF X,Y AXIS UNIDEX

ENCODE $(6,174$, CIDSTG) CR, LF

14 PORMAT ('E $301,2 \mathrm{O}, 1)$

$i$

J=IBUP $(0$, ILVCE, MMDSTG, 6) ! PUT UNIDEX I: EDIT MODE

IE (J.LT.0) STOP ' ERROR - "ESCAN", PUTTI: IG UNIDEX IN EDIT

MDDE'

C

$J=$ IBUP ( O, IDVCE, UPROG, NCUP ) ! WRITE THE SCAN PROGRAM

IE ( J .IT. ' ) STOP ' ERROR - "ESCAN", ZENDING GCAN PROGEAI

DEDN DETA FTE

C

533 ivrite $(5,534)$

534 format (' Enter filename for data ')

$\operatorname{read}(5,535)$ nc, (filena (i), $i=1,40)$

535 format $(q, 40 a 1)$

if (nc.eq.o) goto 5.33

tilena $(n c+i)=0$

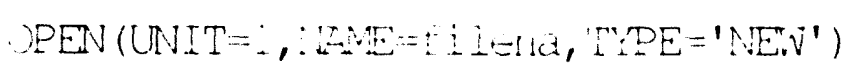

$\therefore$

$\because$ EIRST STEP IS USED TO SIART THE COUNTER

YSPM $=1 . \quad !$ \# OE STEPS PER MICRCN OF $X: Y I S$

TNDBPR $=-$ ?

IRNBPR $=$ TFIK $($ XMOVE $\cdot-\because S P M)$

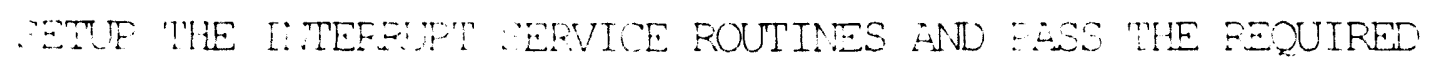

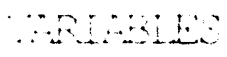

iElau $=0$

ALL TSCAII I EEAG, NDBPE, IRNEEE, TYEITE,

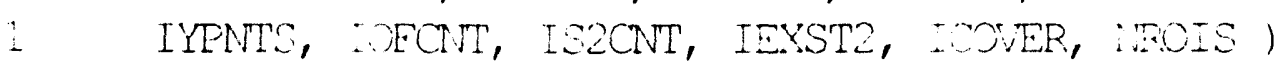




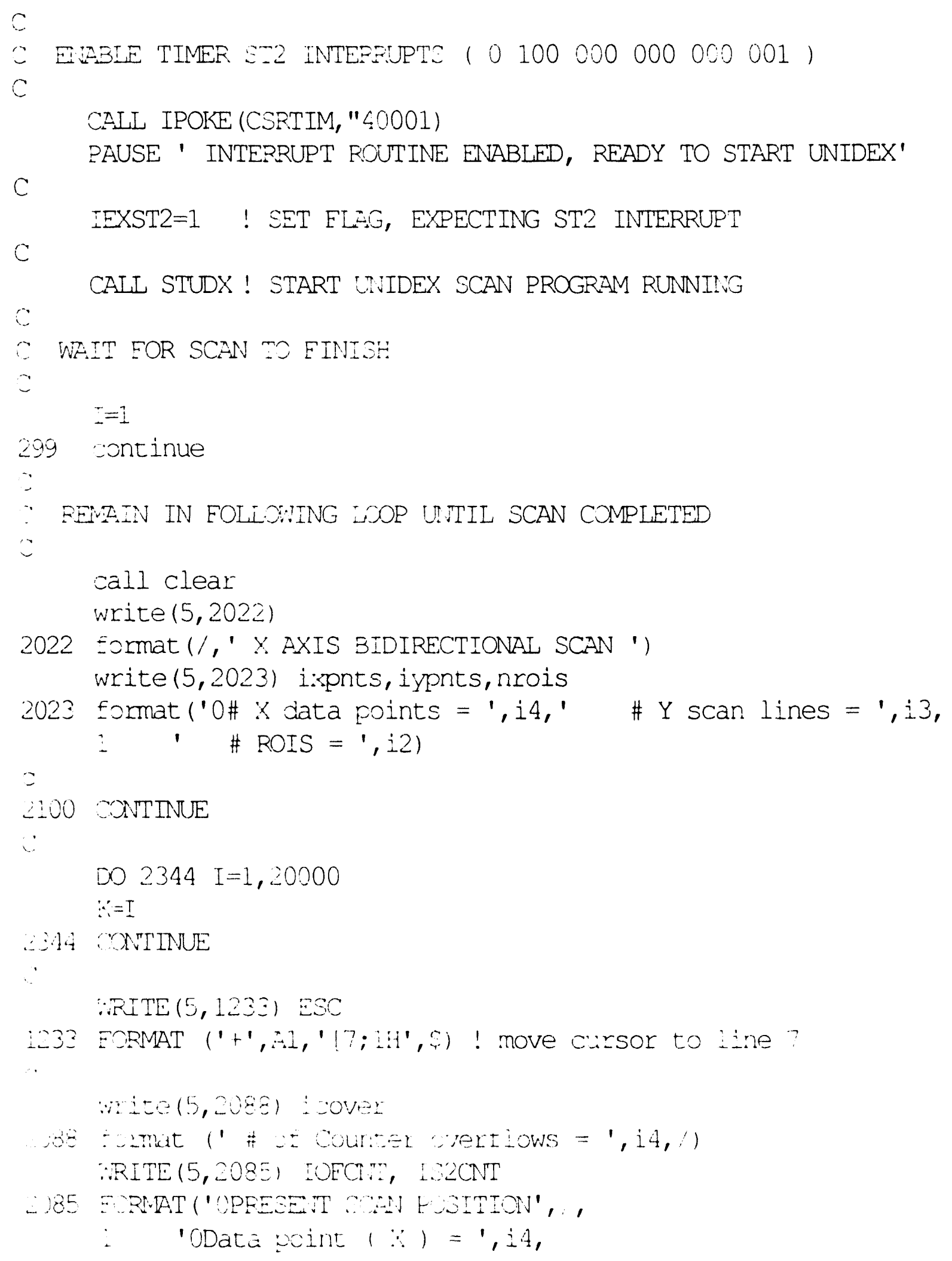




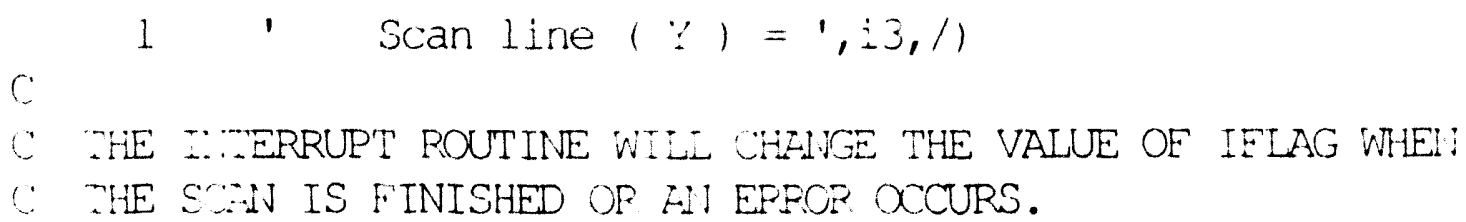

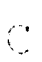

IF ( IFLAG .EQ. O ) COTO 2100 ! LOOP UNTIL EINISH OR. EFROP

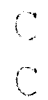

WRI-E $(5,2115)$ IFLAG

$2:=E$ EOETRT (' ELAG $=$ ', I6)

if(ílag.eq.100) goto 2,58

?

wriz $=(5,624)$

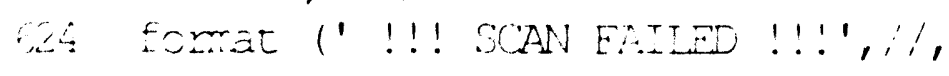

1 'Press RETUPN ta Continue')

got: 14

C CCAN ENISHED, SAVE DATL

$\mathrm{C}$

$258 \quad \operatorname{NRT}=(5,293)$

$29 \%$ EOPIZT ('OSCAN EINISHEL, NOW PETRIEJING AND STORING DATA') (.)

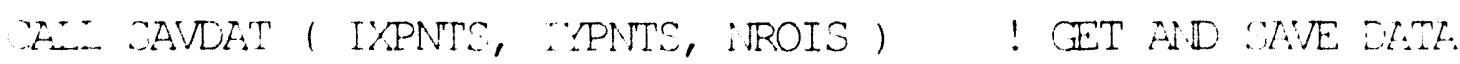

ULCOE (UNTT $=1)$

$J=I E U P(6,2) \quad !$ SERITLL POLL

IE( .LT.0) STOP ' ERPCP. - SEPIEL POLL'

VIFITE $(5,845) \mathrm{J}$

¿45 EOPITT(' SERIAL POLL EITE (OCTAL) $=1,06)$

$j=I E J E(6,2) \quad$ ! SERILI EOLL

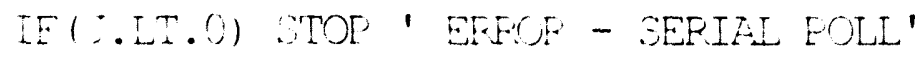

$A F=-\cdots, 845) \mathrm{J}$

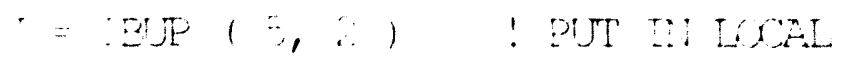

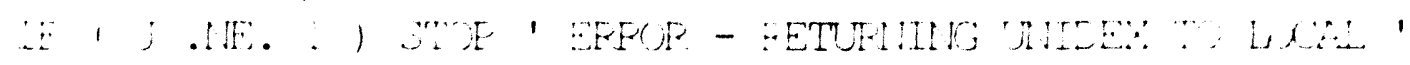

$j=1$

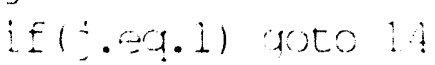


C

999 STOP

END

SUBROUTIIE S EDX

C

C START UNIDEX PEOSRAM

$C$

BYTE CMDSTG(2゚)

C

$$
\text { IDVCE }=2
$$

C

$$
\begin{aligned}
& \operatorname{CMDST}(1)=\prime 1 ! \\
& \operatorname{CMSTG}(2)=1 \\
& \operatorname{CMDSTG}(3)=\prime \\
& \operatorname{CMDSTG}(4)=" 15 \\
& \operatorname{CMDSTG}(5)=" 12
\end{aligned}
$$

C

$$
\begin{aligned}
& J=\text { IBUP (0, ILJCE, CMDSTG, 5) ! WRITE COMMAND } \\
& \text { IE (J.EQ.5) GOTO } 7280 \text { ! JUMP IE NO ERROR }
\end{aligned}
$$$$
\operatorname{WRITE}(5,7182) \mathrm{J}
$$

7182 FORMAT ('OEFEOR - "ESCAV", WRITING START COMMANL,

1 IBUP ERROP $=1, \pm 4)$

$S T O P$

280 CONTITLE

RETUFN

END

subroutine manen:a ( lopt)

integer. is:

it: arite $(2, \cdots)$

A format (')Mais. Gnu', , , 


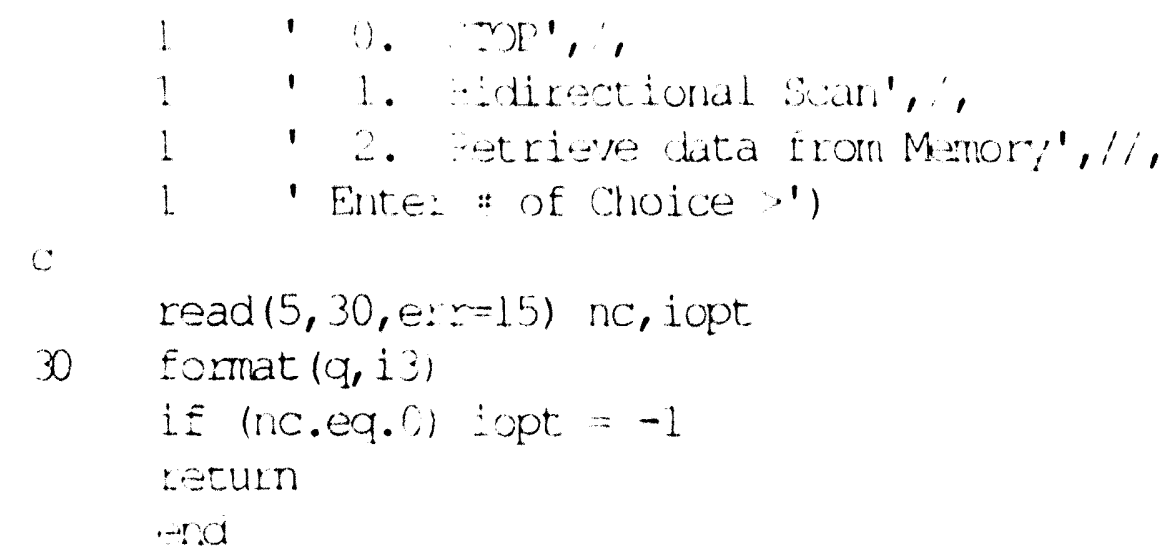

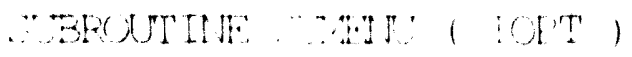

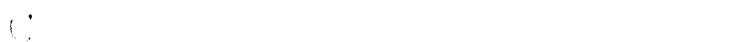

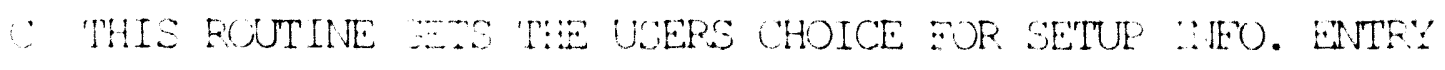

i) CIL CLEAF

VKITE $(5,18)$

18 EORMAT (' $\cdots$ MHU', $1 /$,

1 ' 0 . Main Menu', /,

: 1. $\because$ ile input ',,

i 12. Garuad Input ', $1 /$,

- ENTE: \& OF CHOICE ? ', \$)

$\operatorname{RED}(5,19) \quad \cdots$, IOET

1.) DORMAT ( $(2, \ldots)$

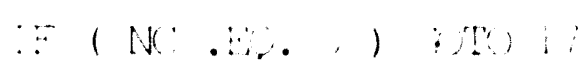

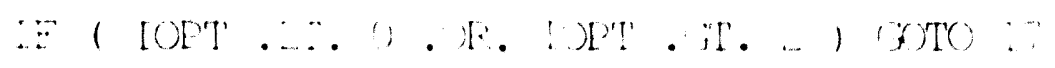

EบUN

$\because \mathrm{I}$ 
ONE: UEAR.ES

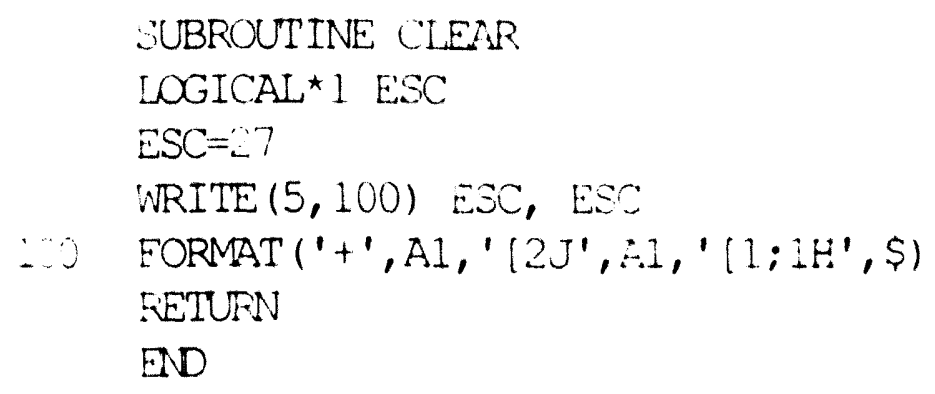


$\because 1$ IAME: $:$ ISR.MAC

$$
\begin{aligned}
& \text {-ticle scan initialization routine } \\
& \text {; } \\
& \text { satim }=: 70410 \quad ; \text { timer } 20
\end{aligned}
$$

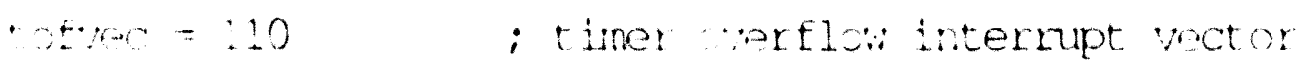

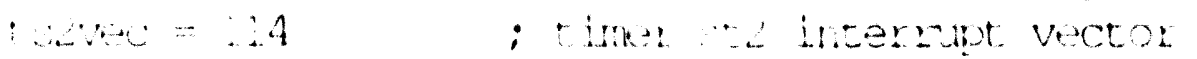

$$
\begin{aligned}
& \text { tlcsr }=: 70420 \quad \text {; counte: } 1 \text { cse address } \\
& \text { tLer }=\text { tlcsr }+2 \text {; countes } 1 \text { bpr address } \\
& \text { thofv }=: 20 \quad ; \text { counts } 1 \text { overflow internupt vector } \\
& \text { cts } 2 \mathrm{~V}=124 \quad ; \text { counter } 1 \text { st2 interrupt vector } \\
& \text { ctacer }=170430 \quad ; \text { counter } \$ 2 \text { csr address } \\
& +\mathrm{Hor}=\mathrm{t} 2 \mathrm{Cs}+2 \text {; counter } \$ 2 \mathrm{kpr} \text { address } \\
& \text { tLofV }=: 30 \quad ; \text { count }=\$ 2 \text { overflow intermpt vector } \\
& \text { t2a.V }=.34 \text {; counte: } \$ 2 \text { st2 interrupt vector } \\
& \text { : Ecsi }=: 70440 \quad \text {; counter \#3 cse address } \\
& \text { whor }=43 \mathrm{csr}+2 \text {; counte: } \$ 3 \mathrm{kpr} \text { address } \\
& \because \text { boly }=140 \quad ; \text { countes overtow interrupt vector } \\
& +3 \mathrm{e} 2 \mathrm{~V}=\mathbf{1 4 4} \quad \text { i count:- ot } 2 \text { interrupt vector }
\end{aligned}
$$

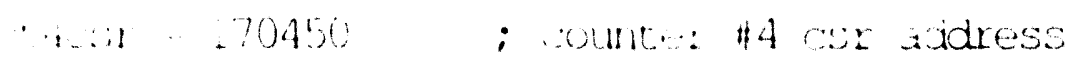

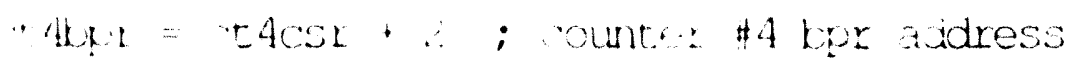

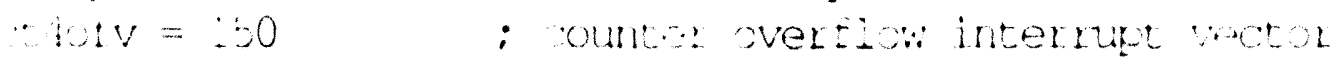

$$
\begin{aligned}
& \text { ths. }=\$ 54 \quad \text {; rourtas st2 intersupt rector }
\end{aligned}
$$




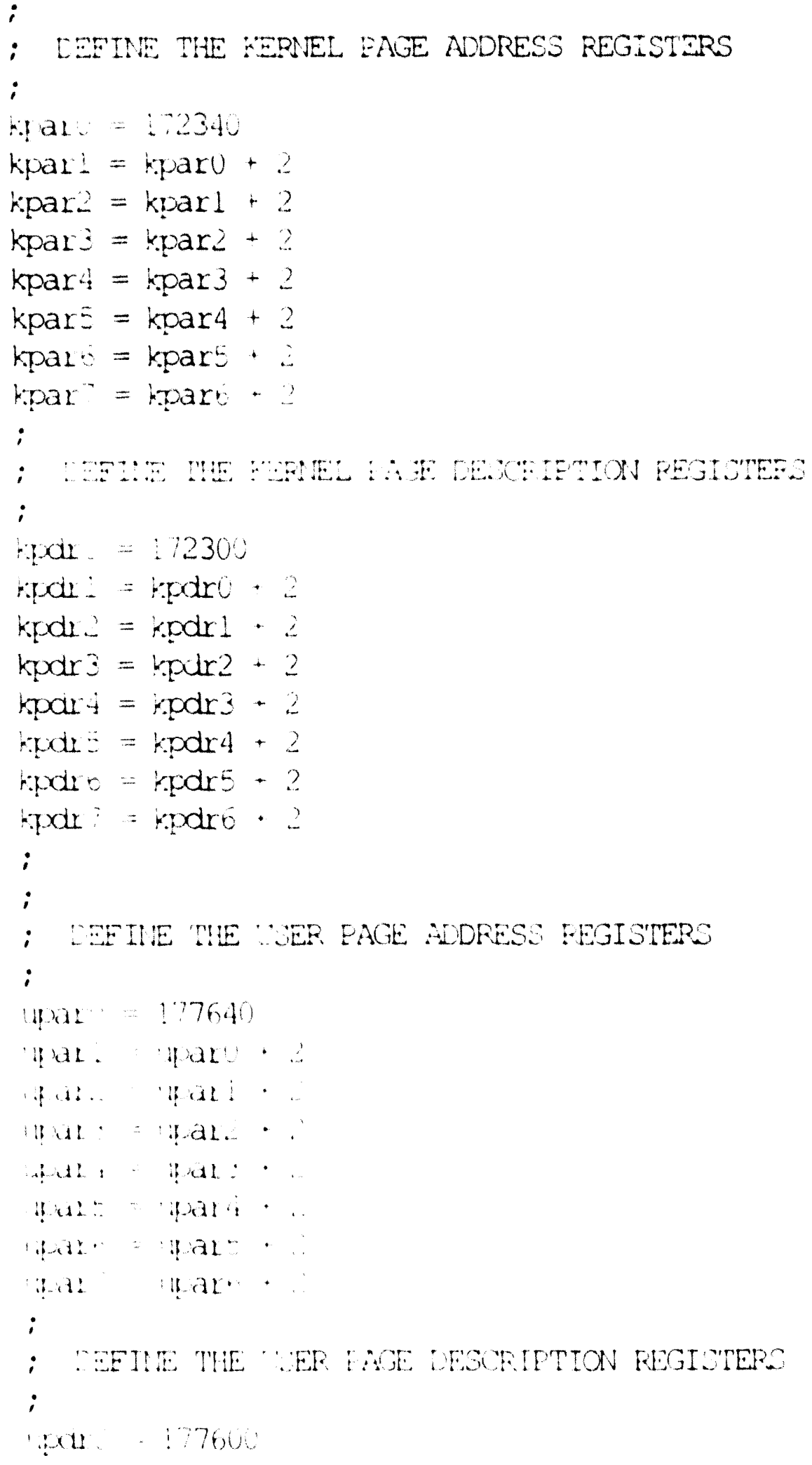




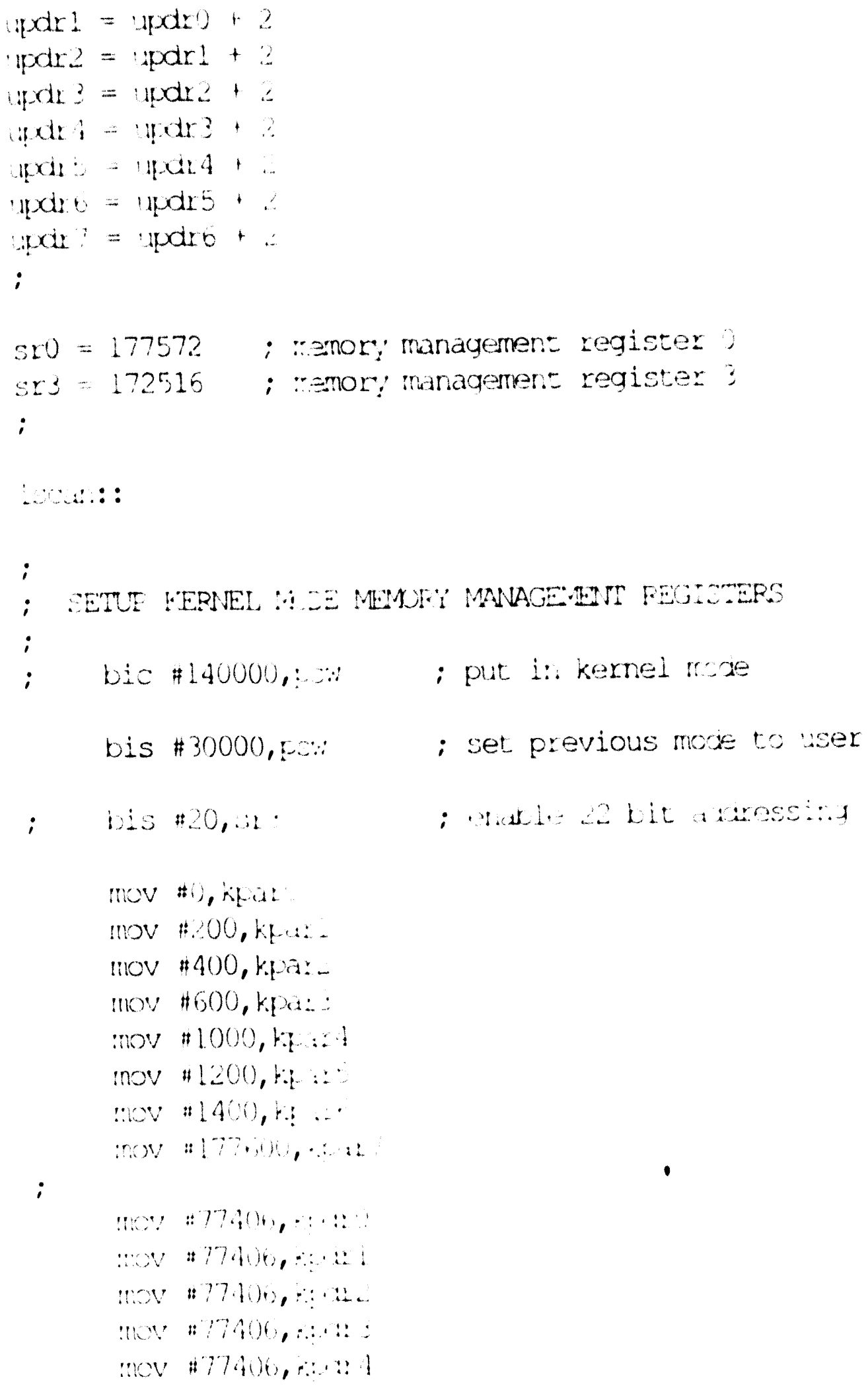




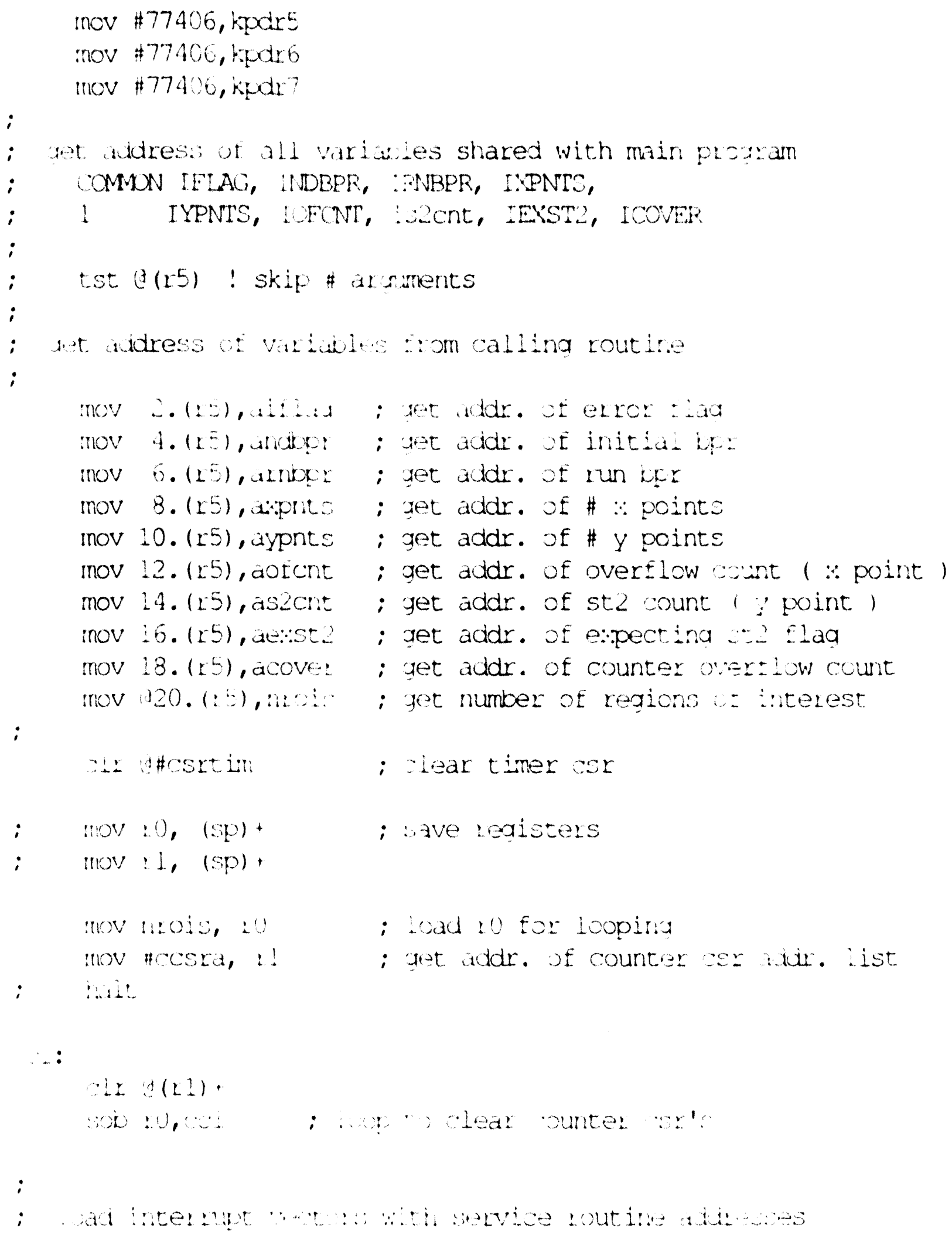


;

nov \#tofist, dtotvec ; timer overflow int. service zoutine mov $\$ 340$, of ofver +2 .

mov \#ts2isr, e\#ts.vec ; tirer st2 int. service routire mov $\# 340$, o \# tazecta.

; all counter werslow internass are randled b: the same toutio

$$
\begin{aligned}
& \text { nov \#cotisr, act Lofv } \\
& \text { nov } \$ 340 \text {, a\# } \\
& \text { mov toot is:, Hackt? } \\
& \text { mov }=30,40.2 \%+2
\end{aligned}
$$

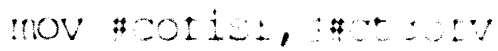

$$
\begin{aligned}
& \text { nov } \$ 340,0 \text { act sotyta. } \\
& \text { mov HCOEISr, a\#CEHOEV } \\
& \text { mov \#340, e\#<ct } 4 \text { of } v+2 \text {. }
\end{aligned}
$$

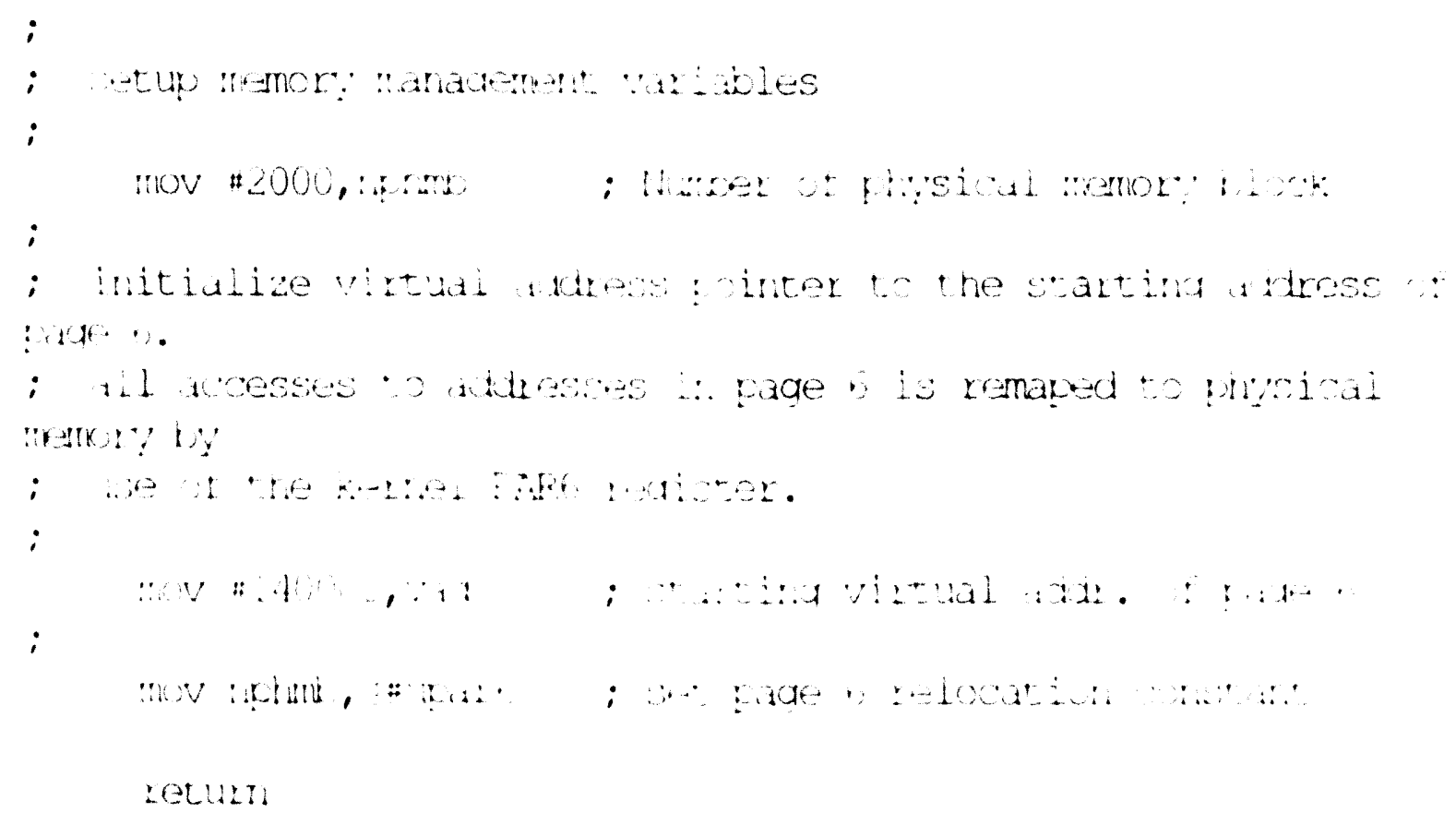




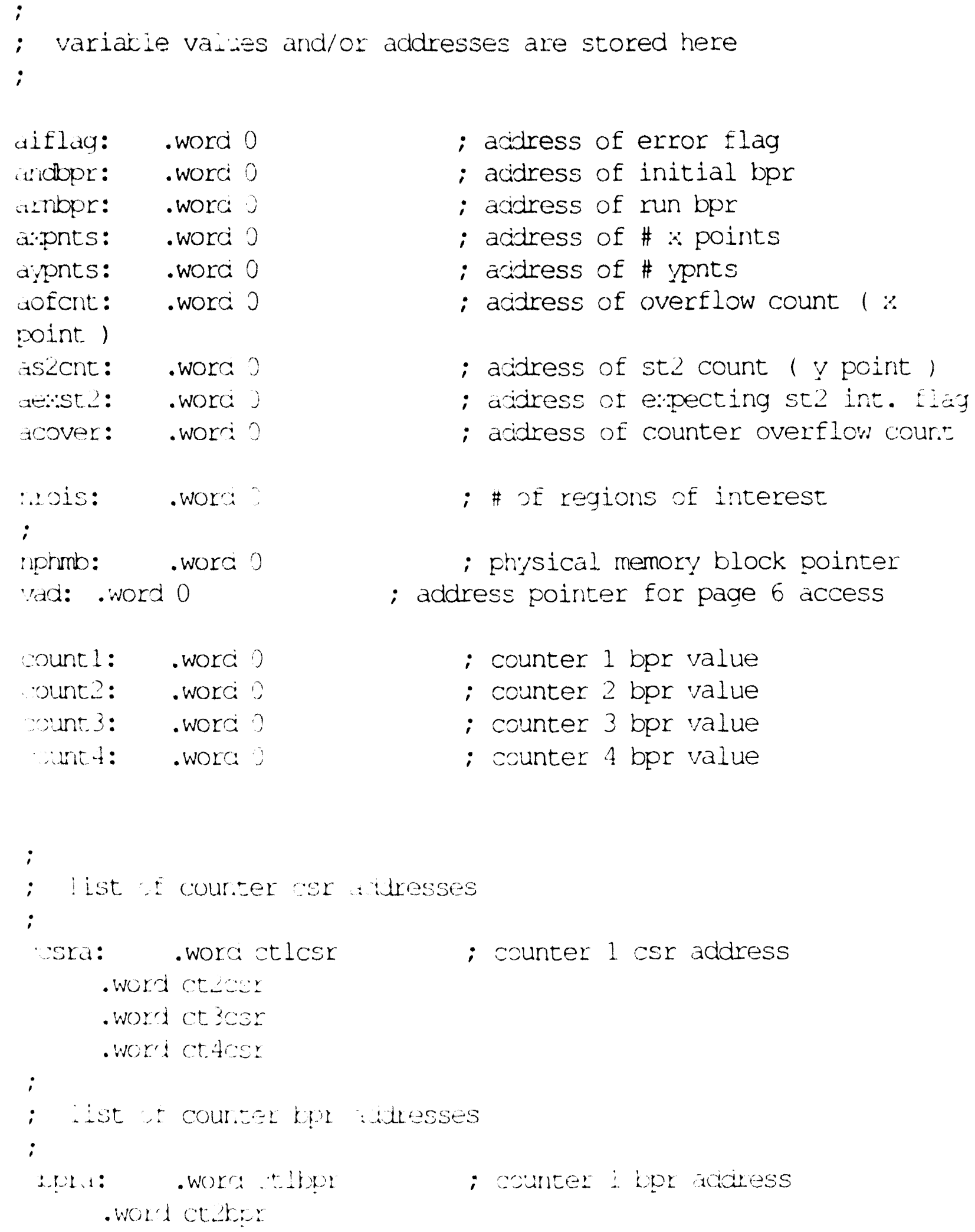


. word ct 3upr

.word ctiber

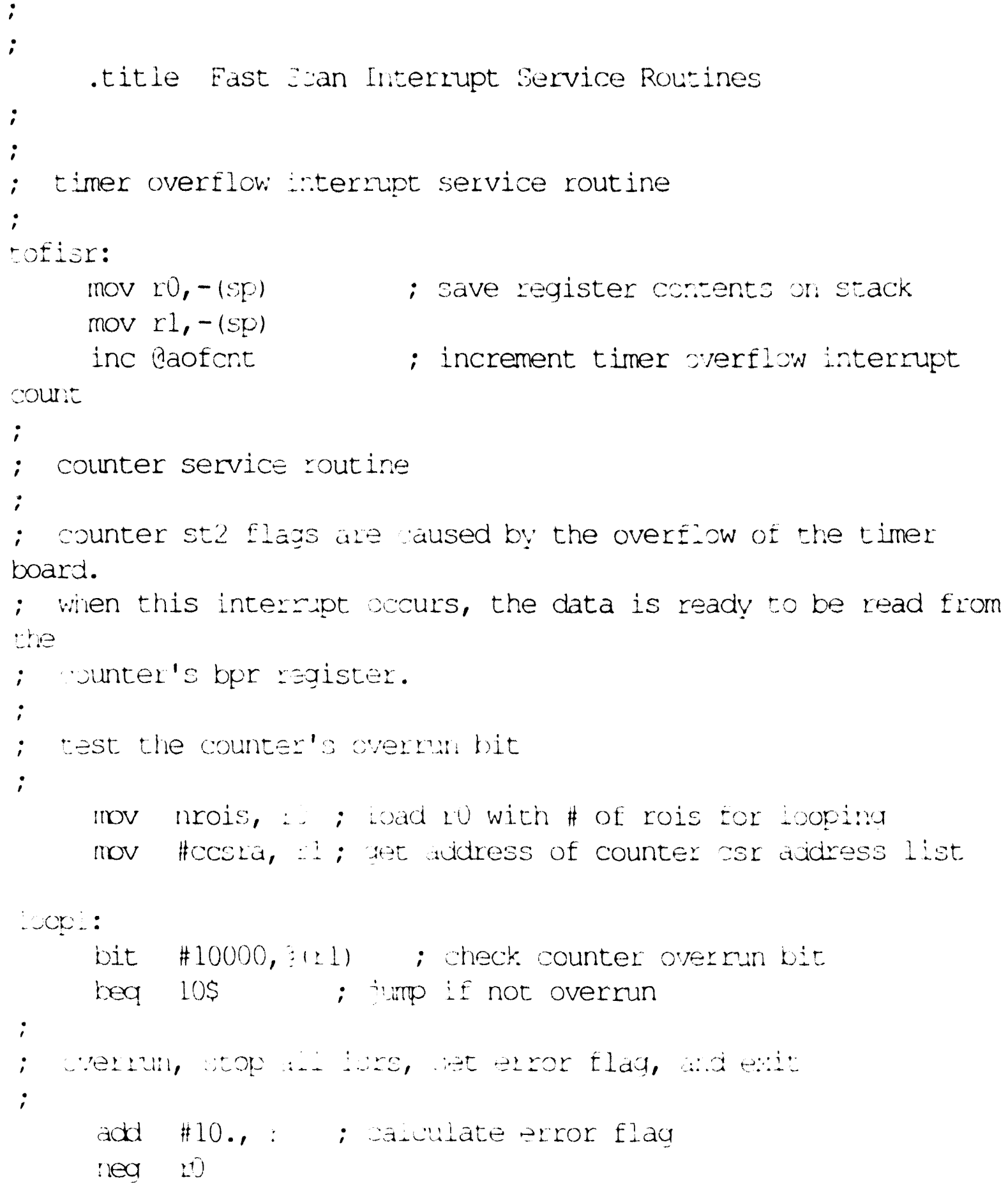




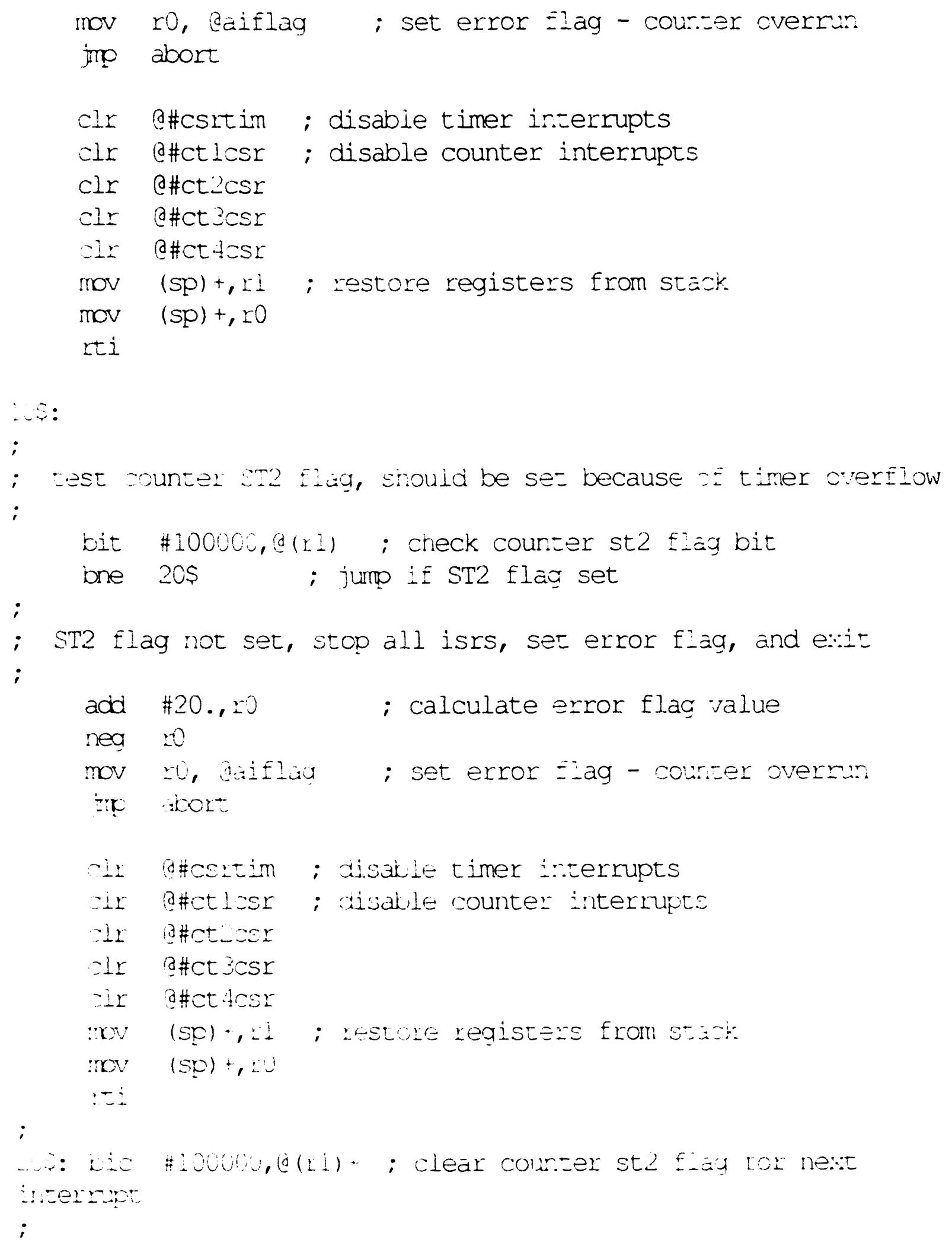




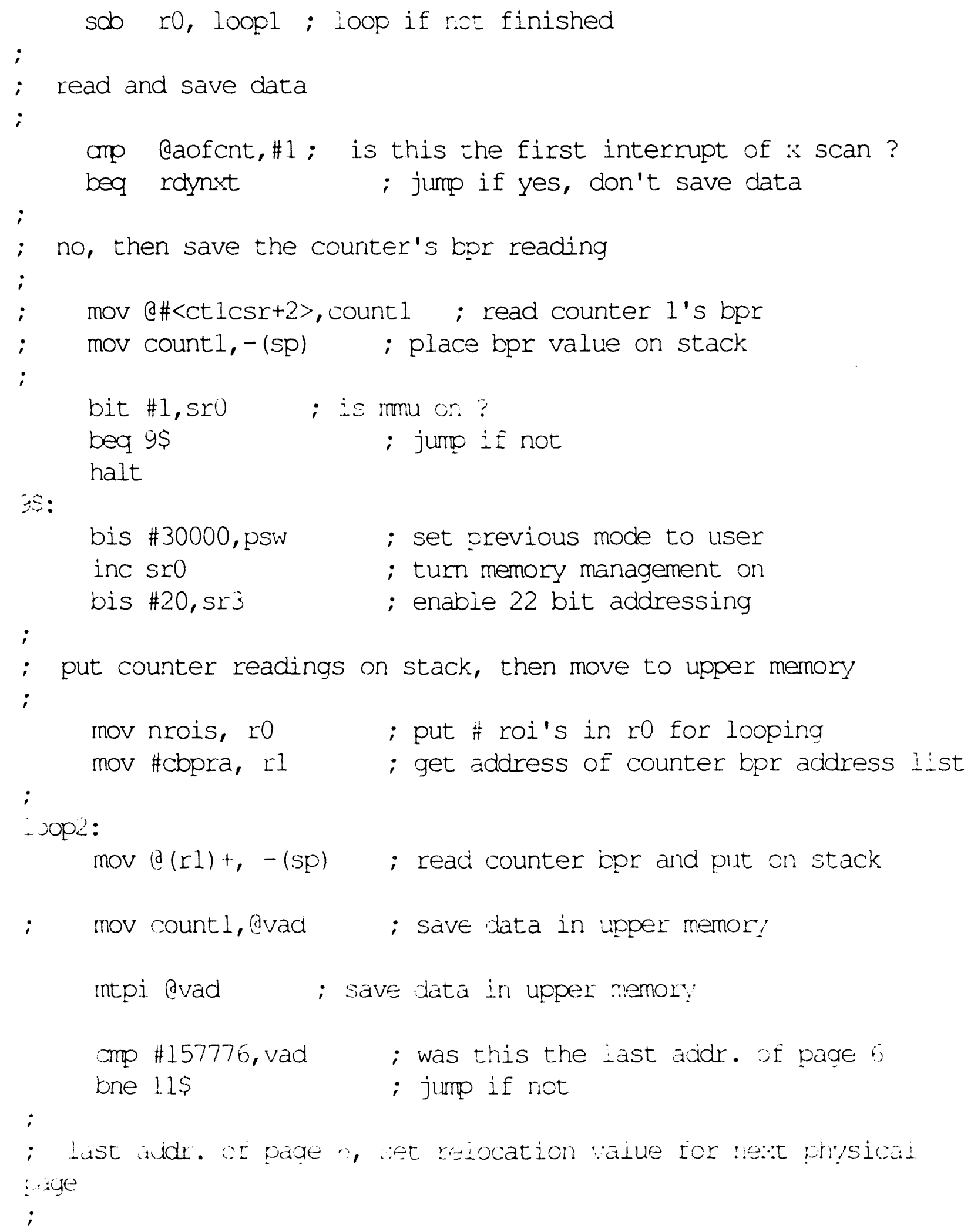




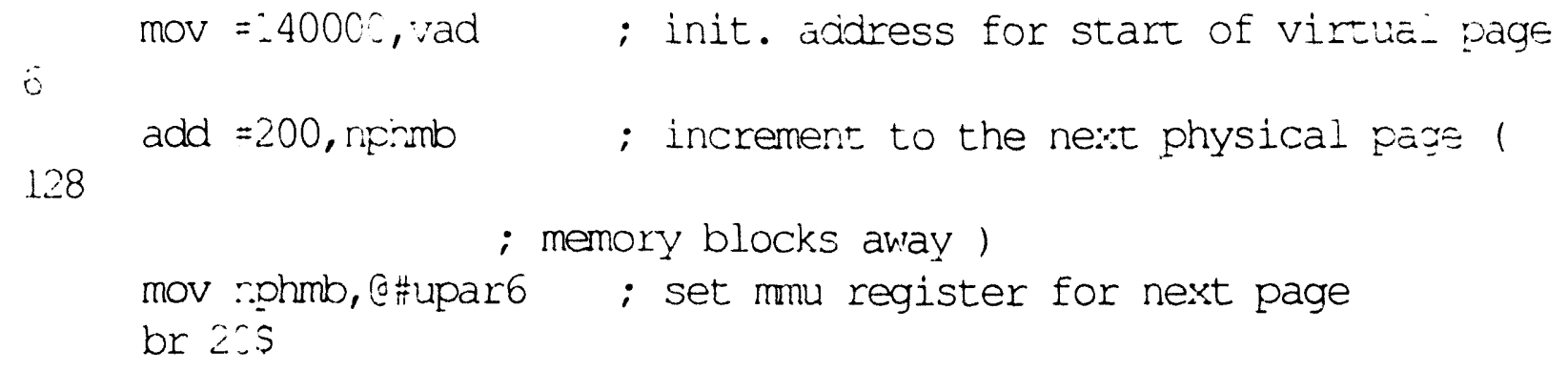




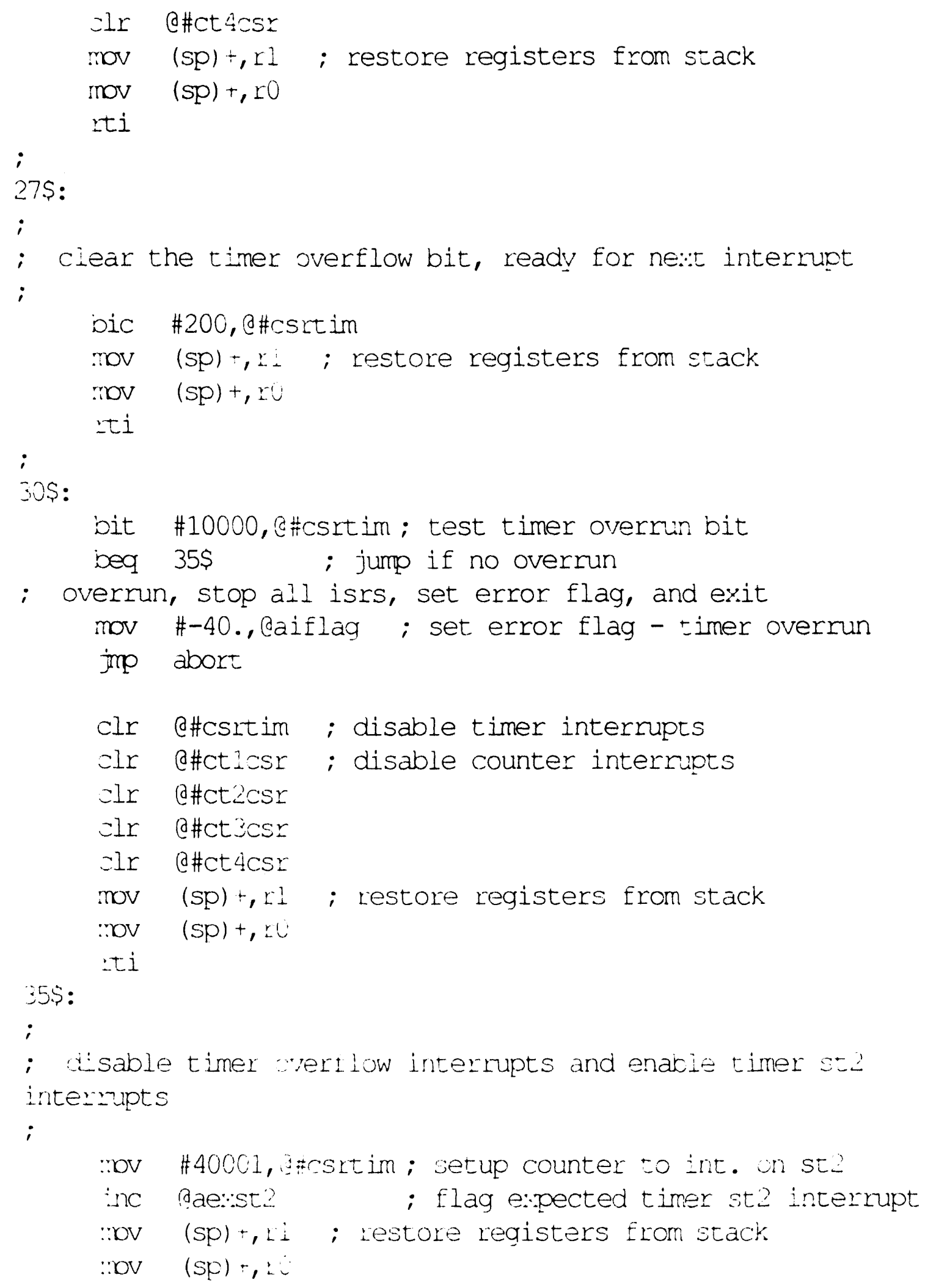


rti

abort:

clr e\#csrtim; disable timer interrupts

mov nrois, ro ; load r0 for looping

mov \#ccsra, rl; get addr. of list of counter csr addr. abrtl:

clr $a(r 1)+\quad$; disable counter intermpt

sob r0,abrtl; loop for each roi

mov $(\mathrm{sp})+, \mathrm{rl}$; restore registers from stack

mov $(\mathrm{sp})+, \mathrm{rO}$

rtj.

\section{ts2isr:}

;

; timer st2 interrupt service routine

;

; timer st2 interrupts occur when the Unidex III has moved into position

; for the next $z$ scan (after $y$ move).

;

; iflag $=100$ when finished

; count \# interrupts to determine when the scan has finished.

;

; clear flag, st2 interrupt not expected before end of next $\because$ scan

;

$$
\begin{array}{ll}
\text { mov } r 0,-(\mathrm{sp}) & \text {; save registers } \\
\text { mov } \mathrm{rl},-(\mathrm{sp}) & \text {; clear flag, not expecting st2 } \\
\text { clr daexst2 }
\end{array}
$$




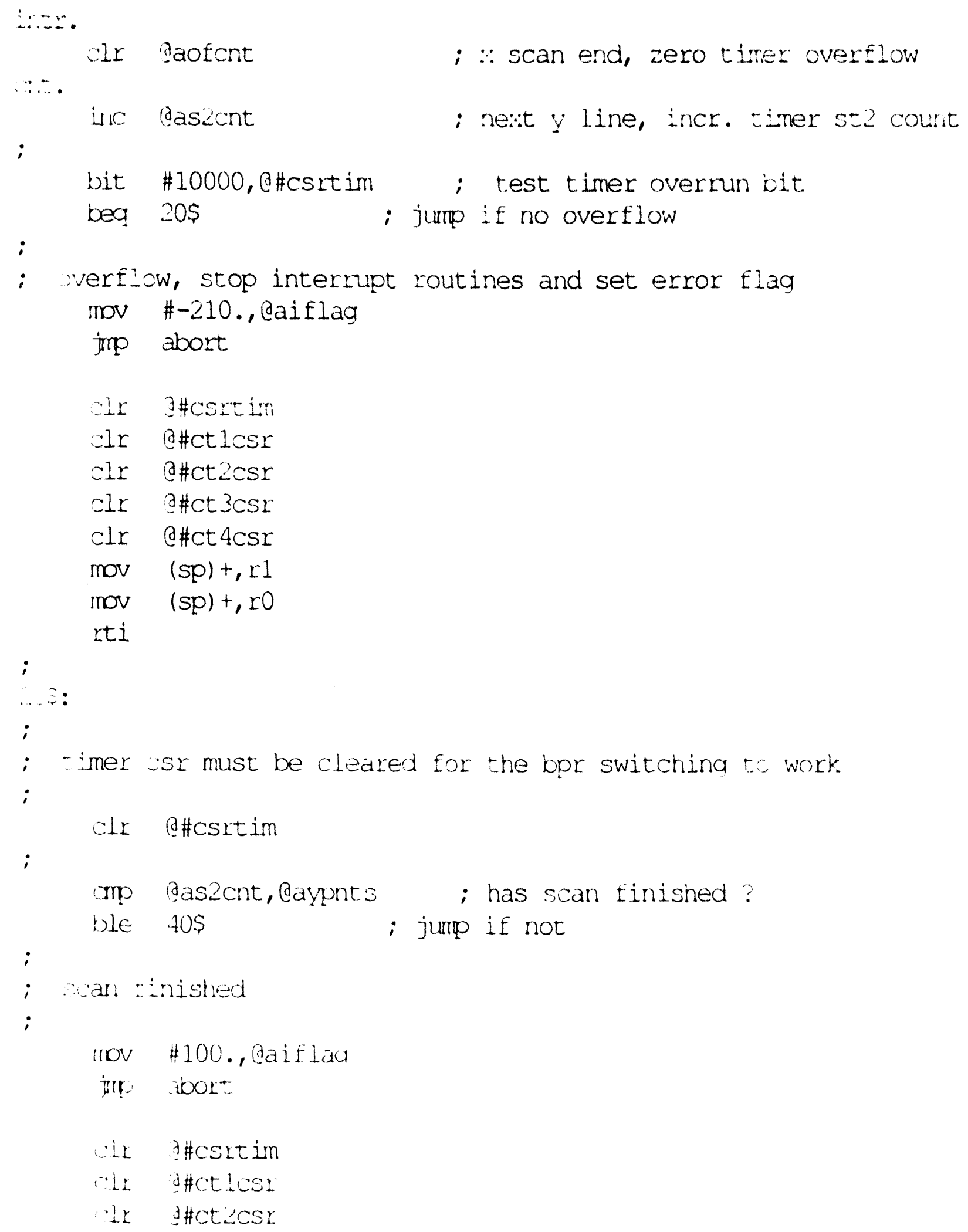




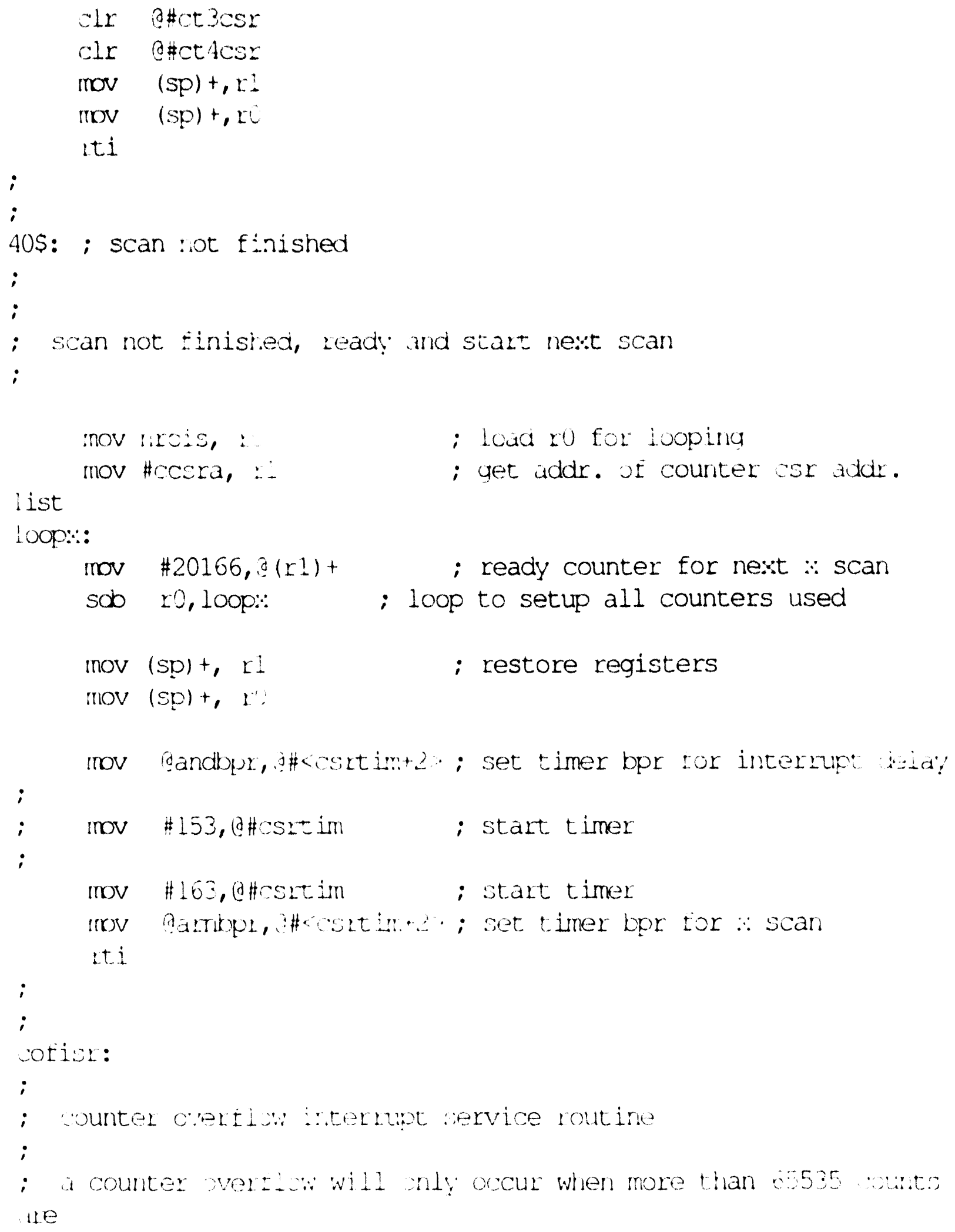


; taken within the specifled count time. If this ocurs, then the counter

; overfluw flag in incremented to keep count ts these occurrences.

;

mov $r 0,-(S p)$
mov $r 1,-(S p)$

mov nrois, : $\quad$; load ro for looping

mov \#ccsra, :1 ; get addr. of counter csr addr. List

loopc:

bit \#100\%,?(t) ; test counter overrur. bit

beq $10 \$$; jump if overmun bit not cet

clr @\#csrim; disable timer interrupts

clr Q\#ctlasr; disable counter interrupts

clr Q\#ct2asr

clr O\#Cticsr

clr e\#ct 4 ssr

; calculate error flag to indicate which counter overflowed.

; since $r \mathrm{l}$ is decremented from the \# of DoIs, the \# of the

; counter roard can be calculated by the fruation

; board $=\#$ ROIS $+1-$ rO

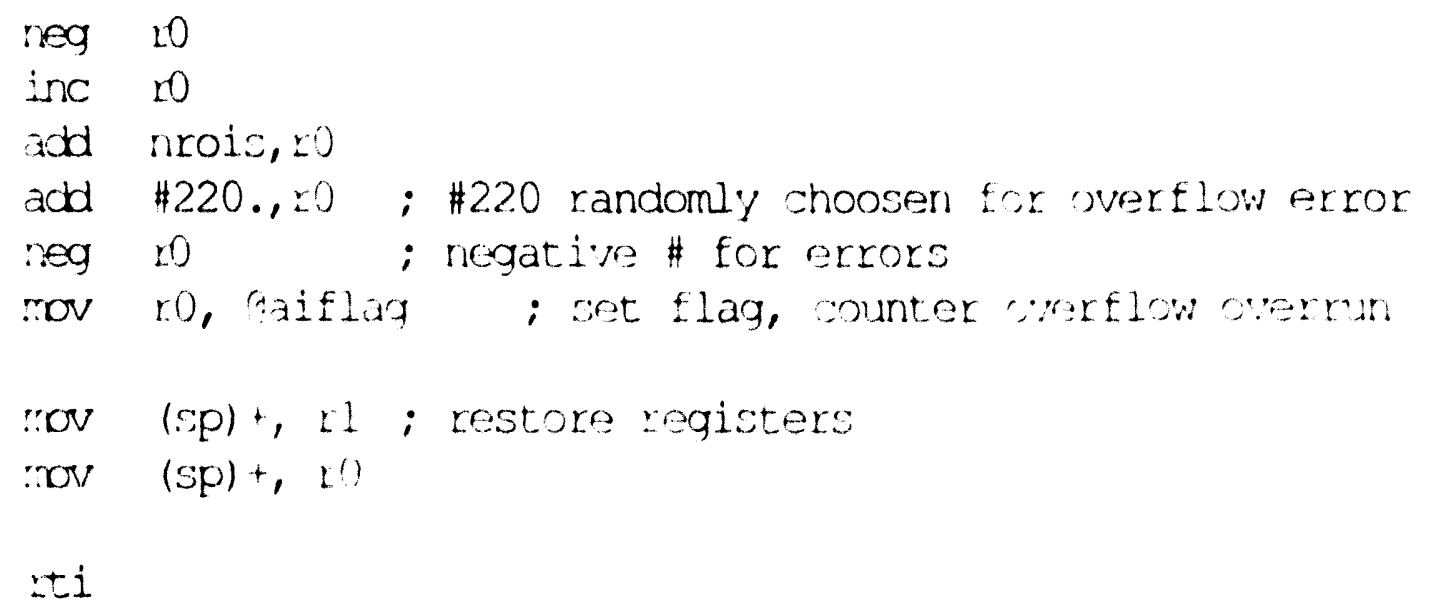


inc dacover i increment counter over:isn count

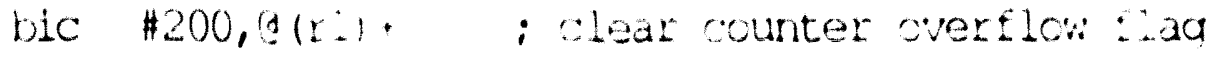

solo ro, loop?; the ail counters

mov $(s p)+,:$; restore registers

nov $(\mathrm{sp})+$, :

rti

;

; his routine iritializes the variables for the point zutine

;

NGt: :

mov \#0, kparo

mov \#200, kpar:

mov \#400, kpar.

mov \#600, kpar:

inov \#1000, kpar4

mov $\$ 1200$, kpar

inuv \#1400, kpars

mov \#177600, kas:

:10V \# 77900, hedes

mov $\$ 77406$, gries:

mov $\$ 77406$, kman

mov $\$ 77406$, blow

mov \$77406, kpard

inov $\$ 77406$, kpors

mov $\$ 77906$, kicir.

:1) \#77115, iras

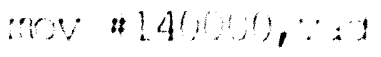

now tavol, aper:

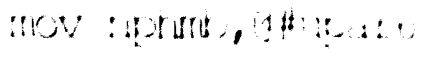

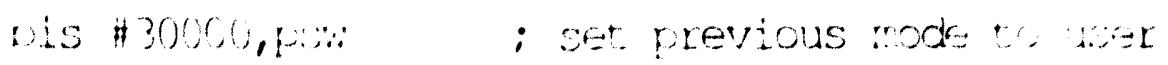


bis $\# 30000$,psw

; bis $\# 20$, sr3 return
; set previous mode to user.

; enable 22 bit addressing

;

; this routine operates sexuentially, after the value of the data point

$;$ is passed to the calling routine, it increments a pointer to the next

; data point value. "iget" must be called before calling this

routine

; since it initializes the variables used here.

;

getpnt: :

bis \#30000,psw ; set previous mode to user

inc $s r 0$

; turn memory management on

bis \#20,sr3

; enable 22 bit addressing

mfpi evad

clr sr3

clr sro

; read value from upper memory to stack.

; disable 22 bit addressing

; turn mmu off

mov $(\mathrm{sp})+$, count 1

mov count 1,02 . ( 15$)$; pass the value to the calling routine

cmp \#157776, vad $\quad ;$ is this the last addr. on page 6

bne 14\$

i jump if not

mov \#140000, vad

; set virtuai addr to beginning of page 5

add \#200, nphmb

; increment memory block to nest ch\%.

page

mov niphmb, @\#upar6 ; setup rmu register for remap

br $19 \$$

$14 \$:$

inc vad 
195:

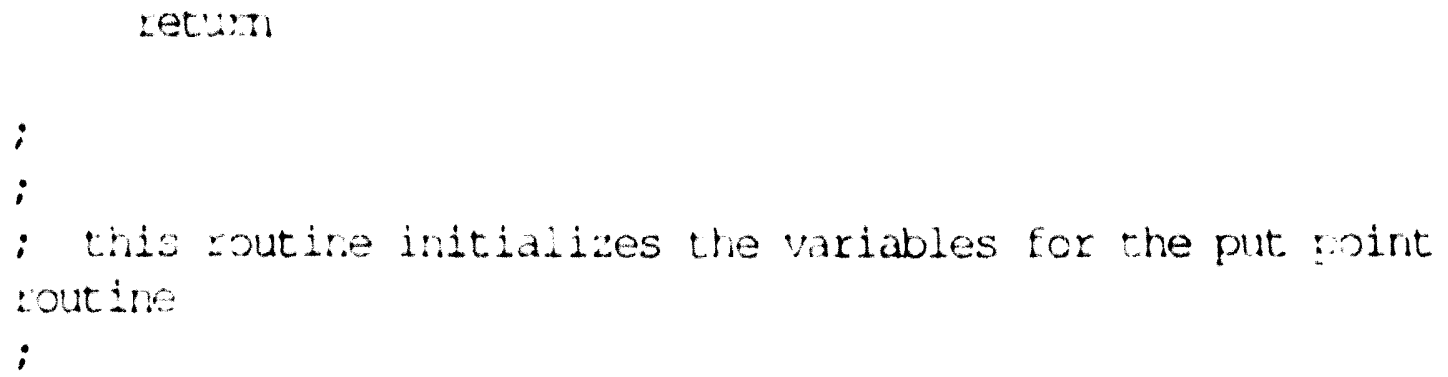


; this routine crerates sequentially, after the value of the data point

i is passed to tris routine, it increments a pointer to the next - data point address. "iput" must be called befo.e calling this routine

; since it initializes the variables used here. ;

putpnt: :

bis \#30000, Fs:l ; set previous mode to user

mov 2 . (r5), sount1; get the value from the calling routine

mov count $1,-(\mathrm{sp})$; put it on the stack

inc sro

; turn memory management on

bis $\# 20$, sr 3

; enable 22 bit addressing

mtpi dvad

; move value from stack to upper memory

clr sr3

; disable 22 bit addressing

cle sro

; turn rmu off

cmp \#157776, vad

i is this the last addr. on page 6

bne $14 \$$

; jurmp if not

mov \#140000, $\because \mathrm{ad}$

; set virtual addr to beginning of page 6

add \#200, nprmid

i increment memory block to next phy.

page

mov nphmb, (apar6 ; setup mu register for remap

br $19 \$$

14\$:

inc vad

inc vad

; increment to ne:st data point address

19\$:

retum

.end 
FLENAME: GETBDS.E:?

SUBROUTINE CEEES ( :OPT, NROIS, IXPNTS, :YPNTE, DDIR, 1 ZFEEE, YMOVE, YDIR, YFEED, YMOVE)

E

THIS ROUTINE GETZ THE EETA TO PROGRAM THE GIIDE: II EOR A ETDIRECTIONAL

SCAN.

LOGICAL*] FIIEZ

inteaer. iopt

$Z S P M=1 . \quad$ ! \# $Y$ Y YEES PER MICFON ON X $\because X S$

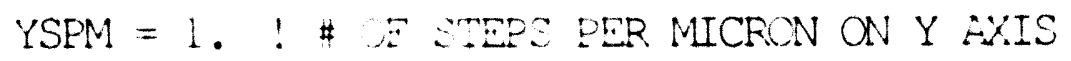

GET SETUP INFO. FROM EIIE IF SELECTED

C.

IF ( IOPT .EQ. : ) CALL EILESU ('R', IXPNTS, OOVE,

1 XFEE, IYPNTS, :MOVE, YEEED,

1 NROI:, IQUAD )

IF ( IOPT .EQ. : ) GOTO 141

chnor $={ }^{\prime} N$ '

31 ALL CLEAR

C CNITINE

4) OONTINUE

IF (CHNG.EQ. $\because "$, WRITE $(5,343)$ IDENTS

$\because 3$ FORMAT (' MUMEE OE $\because$ EOINTS $=1$, I6)

LE (CHNG.EQ.' ':!' 'WRITE $(5,41)$

$\therefore$ FORMAT(' MUMEEE OF $\because$ POINTS ( 0 TO 32767 FOR LANE ECAN) : ') READ $(b, 12) \quad 1, \cdots, \ldots \mathbb{N}$

2 EORMAT (2, $2 \%$

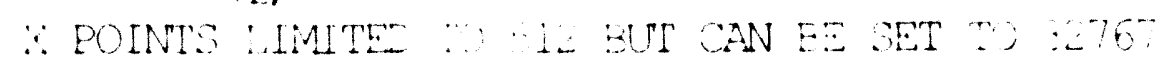

HANGE TO 3276 : : $1:-2-88$. DAC. 
IE (NC.EQ.0.AND.CHNG.EQ.' " ' ) GOTO 20 IF (NC.EQ.O) GOTO 40

IF (INUM.LT.O.OR. INUM.GT. 22767) GOTO 40

IXPNTS $=$ INUM

X) CONTINUE

IF (CHNG.EQ. 'Y') WRITE $(5,23)$ XMOVE

23 FORMAT ( $X$ POINT SIZE ( MICRONS ) = ',E15.1)

IF (CHNG. EQ. ' $N$ ') WRITE $(5,21)$

2 EORMAT (' $X$ POINT SIZE $1 . .1$ TO 1000 MICRONS ) ?')

PEAD $(5,22)$ NC, ENTM ! \# STEPS TO MOVE AXIS FOR IELT POINT

2 EORMAT $(2, \mathrm{E} 15.0)$

MAX. $\because$ MOVE IS 2, $000,000,00$,

IF (NC.EQ.O.AND.CIING.EQ." $\because "$ ) GOTO 30

IF (NC.EQ.0) GOTO 20

XSPP $=$ AINT ( mum * XSPH $) \quad !$ CALC. \# OF steps $2.1 \times$ MOVE

IF ( XSPP .LT. 1.0 .OR. $\because$ SPP .GT. 10000.0$)$ GOTO 20

$X M O V E=R N U M \quad$ : DATA POINT SIZE (MICRONS)

3 CONTINUE

TSMIN $=6.0 \mathrm{E}-6 \quad !$ MINIMUM TIME PERIOD PER STEP

TSMAX $=4000.0 \quad !$ MAXIMUM TIME PERIOD PER STEP

TPMIN $=$ TSMIN $\star X M O V E !$ MINIMUM TIME PER DATA POINT

TPMAX = TSMAX $*$ XMOVE ! MAXIMUM TIME PER DATA FOINT

IF (CHNG.EQ. ' $Y$ ') WRITE $(5,33)$ XFEFD

$\therefore$ FORMAT (' TIME FER POINT ( SECONDS ) $=1$, E15.6)

IF (CHNG.EQ. 'N') WRITE $(\%, 31)$ TPMIN, TPMAX.

$\therefore$ CORMAT(' TIME per ? POIM ( ',E15.5,' TO ', E15.0,' aECAOS ) (')

READ $(5,32)$ IC, EMM ! FEEDRATE ECR MOVES BETWEE: COTMO

$\therefore \quad$ SORMAT $(2, E 15.6)$

EEEDRATE LIMIT OE 10,000 CHOSEN BY FEOGRAMMER AAN EE OAAUED

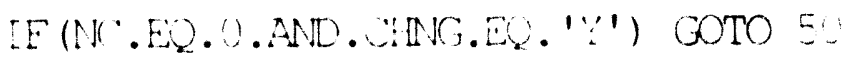

IF (NC.EQ.U) OTO

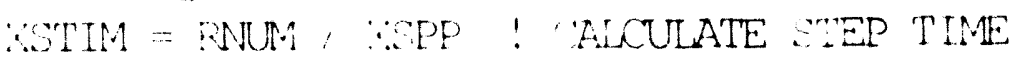

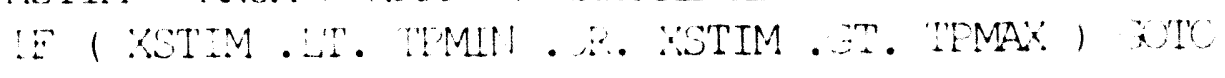

CFEEDERNNM 
C

50 CONTINUE

(1) continue

C

90 CONTINUE

IF (CHNG.EQ. ' $Y$ ') WRITE $(5,293)$ IYPNTS

293 EORMAT(' NUMBER OE Y POINTS $=$ ', I6)

IF (CFNG.EQ. 'N') WRITE $(5,91)$

91 EORIET (' NUMBER OF Y POINTS ( I TO 512 ) ? ') $\operatorname{REAL}(5,92) \quad N C$, INUM

$92 \quad$ FORIET $(Q, I T)$

C Y POIITS LIMITED TO 512 BUT CAN BE SET TO 32767

IF (I.C.EQ.C.AND.CHNG.EQ.'Y') GUTO 70

IF (IC.EQ.C) GOTO Yo

IE (IIUM.LI.2.OR. INUM.GT.32000) GOTO 90

IYPI:TS=INUM

C

70 CONTINUE

IF (CHNG.EQ. 'Y') WRITE $(5,273)$ YMOVE

273 FORIMT(' $\because$ MOVE ( MICRONS ) = ', E15.0)

IE (CHNG.EQ. 'N') WRITE $(5,71)$

71 EORIMT(' $\because$ MOVE ( 0.1 TO 1000 MICRONS ) ?')

REEI $(5,72)$ NC, RNUM ! \# OE STEPS TO MOVE Y AXIS EOR NEXT ECZN

72 EORINAT $(Q, E \div 5.0)$

C MAX. $\because$ MOVE IS 2,000,000,000

IF (IC.EQ.O.AND.CHNG.EQ.' Y') SOTO 80

IE (ITC.EQ.O) GOTO 70

MMS $=$ mum $*$ YSPM $! \#$ OF steps in $Y$ move

IE ( YMS ..T. 1.0 .OR. MS .G. I0000.0) GOTO 70

YMONE=RNUM!

o) cortinue

$c$

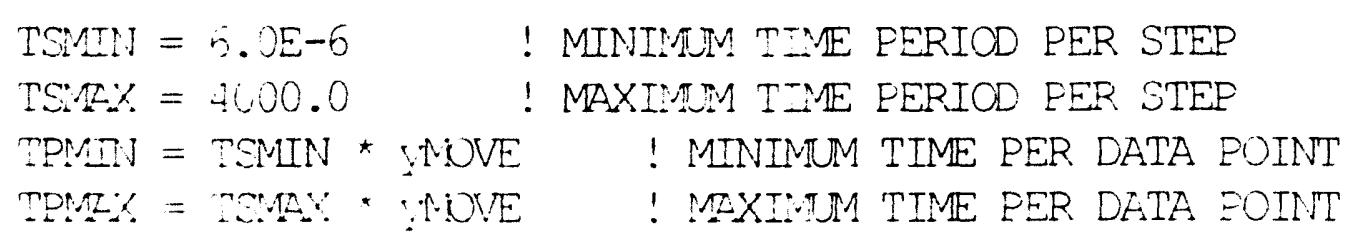


IF (CHNG.EQ. ' $\because$ ') WRITE $(5,283)$ YFEED

283 EORMAT ( $\because$ MC' $\equiv \operatorname{TIME}(\operatorname{SECONDS})=1$, E1 1.6 )

IF (CHNG. $E 2 . ' \cdots '$, WRITE $(5,81)$ tpmin, tpmä:

81 EORMAT(' TIME cer Y MOVE (',e15.6,' TO ', el5.б,' SECONDS )

?')

READ $(5,82)$ M, ZNUM ! FEEDRATE EOR MOVES BETWEEN POINTS

82 FORMAT $(Q, E 15$. . $)$

IF (NC.EQ.O.AIE.CHNG.EQ. 'Y') GOTO 100

IF (NC.EQ.O) GO.O 80

YSTIM = RNUM : IMS ! CALCULATE STEP TIME FOR Y MOVE

IF ( YSTIM .I:. Epmin .OR. YSTIM .GT. t:ma\% ) GOTO 80

YEEEDERIIII

100 CONTINUE

i1j continue

C

129 CONTINUE

$\mathrm{C}$

3110 CONTINUE

IF (CHNG.EQ."'?') WRITE $(5,5113)$ nrois

5113 format (' MUMEE: OE ROIS = ', I3)

IF (CHNG.EQ. ':.') WRITE $(5,3111)$

311 EORMAT (' How wany ROIs ? ( $1-4)^{\prime}$ ')

$\operatorname{READ}(5,3112)::$, inum ! \# of regions of interest

$\because 22$ EORMAT $(2, \pm 15 . ;)$

IF (NC.EQ.0.AE.CHNG.EQ.' Y') GOTO 3129

IE (NC.EQ.0) $=103110$

IF (RNUM.LT. . .OR.FINM.JT.4.0) GOTO 31:0

nrois $=$ NUL:

329 continue

¿.44 IE (CHNG.EQ.' '.') write $(5,1345)$

$\$, 45$ tormat 1

1 ' The inziai bearn location on', i,

' tre y.men is the origin.', i,

' ', , 


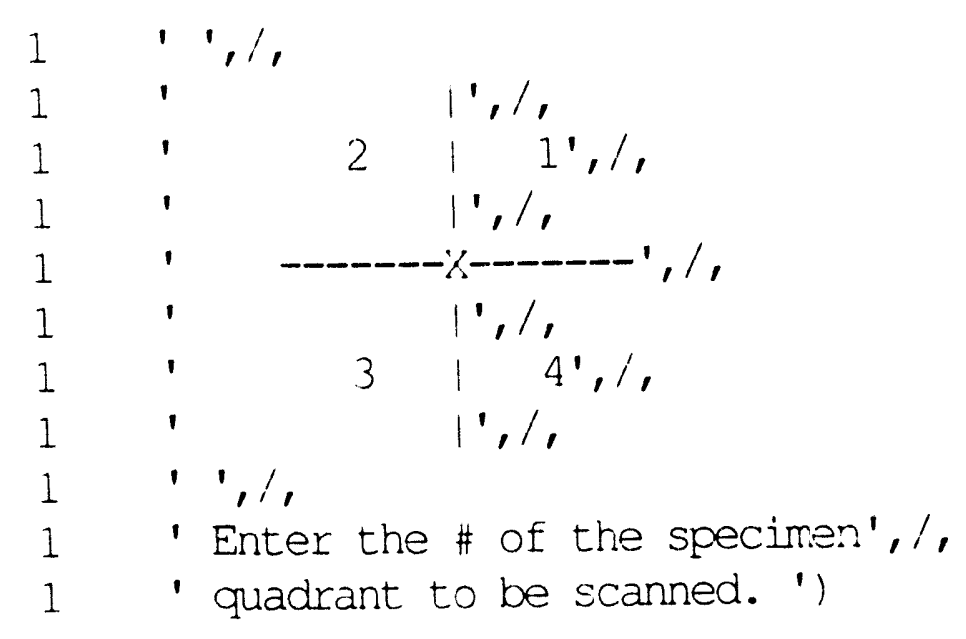

IE (CHNG.EQ.' ' ' ) WRITE $(5,5333)$ ICUED

0333 EORMAT (' SPECIMEN SCAN QUADRANT $=1$, I3)

c

$\operatorname{read}(5,1346) \mathrm{NC}, \mathrm{Ii} \pi M$

1346 format $(Q, 12)$

IF (NC.EQ.0) GOTO 141

if (iNUM.1t.1.or.iNUM.gt.4) goto $=344$

C

IQUAD $=$ INUM

$\because$ dir $=1.0$ ! define $\because$ direction for quadrar: \#1

$y$ dir $=-1.0 \quad$ ! define $y$ direction for ciadrant \#1

if (iquad.eq.2.or.iquad.eq.3) $x$ dir $=-x$ dir

if (iquad.eq.3.or.iquad.eq.4) ydir $=-$ ydir

i.11 OONTINUE

CALL CLEAR

WRITE $(5,43)$ IXPNTS, XMPVE, $Y$ FEEL

4. EORMAT ( 1 NUMBER OF $\times$ POINTS $=1, \pm 0,1$,

$i$ ' $X$ POINT SIZE ( MICRONS ) $=1$, E15. 2, ,

$\therefore$, TIME PER POINT ( SECONDS: = ',E15.

WRITE $(5,53)$ IYPNTS, ymove, yfeed

a: EORMAT (' NUMBER OF Y POINTS $=1, I 6,1$,

$\therefore \quad I Y \operatorname{MOVE}(\operatorname{MICRONS})=1, \mathrm{E} \pm \equiv .0,1$, 
1 ' Y MOVE TIME ( SECONDS ) = ',F15.6)

write $(5,3113)$ nrois, ¿quad

$\therefore 13$ format (' NUMBER OF FOIS $=1,13,1$,

1 ' SPECIMEN SCAN QUADRENT $=1$, i3)

$C$

$z$ dir $=1.0$ ! define $\because$ direction for quadrant \#1

ydir $=-1.0 \quad$ ! define $y$ direction for quadrant \#1

if (iquad.eq.2.or.iquad.eq.3) xdir $=-$ ydir

if (iquad.eq.3.or.iquad.eq.4) ydir $=$-ydir

I

XSPP = AINT $($ XMOVE * XSPM $) \quad !$ CALC. \# OF stepS INJ X MOVE YSTIM $=$ XFEEL $:$ XSPE $!$ CALCULATE STEP TIME

YMS = AINT ( YMOVE * YSPM) ! \# OE steps ir: Y move

YSTIM = YFEED $;$ YMS ! CALCULATE STEP TIME FOR Y MOVE

C

XFDR $=1.0 /$ XSTIM $! X$ FEED RATE

YEDR $=1.0 /$ YSTIM $! Y$ FEED RATE

$C$

WRITE $(5,483)$ XSPP, XSTIM, XEDR, YMS, YSTIM, YEDR

483 EORMAT ('OCALCULATIONS ', //,

1 1 \# X STEPS PEF. EOINT $=1$, E15.0,1,

1 ' $X$ STEP TIME $=1$, E15.5, 1 ,

1 ' X FEED RATE $=1$, E15.3,1,

11 \# Y STEPS PEP. MOVE $=1, E 15.0,1$,

1 ' Y STEP TIME $=1, E 15.6,1$,

1 ' Y EEED RATE $=$ ',E15.3)

170 WRITE $(5,171)$

171 FORMAT ('OCHANGES ! CORRECTIONS ? ')

$\operatorname{READ}(5,172) \quad \mathrm{CHNG}$

$\because$ EORMAT (AI)

IE (CHNG.EQ. ":!") XITC : $: 0$

IF (CHNG.NE.' $Y$ ') OTC 170

WRITE $(5,173)$

073 EORMAT ('OENTER NEW VFLUE OR LEAVE BLANK TO RETAMN PEESENT 'P.L,UE. ' )

SOTO 782 
C

120 CONTINUE

WRITE $(5,121)$

121 EORMAT ('OSAVE SCAN SETUP ?')

$\operatorname{REAL}(5,122)$ ANS

122 FORMIT (AI)

IF (FNS.EQ. 'N') GOTO 130

IE (ANS.NE. 'Y') GOTO 120

$\mathrm{C}$

$C$ IRITE SETUP IIEO. TO FILE

C

CALL EILESU ('W', IXPNTS, XMOVE, XFEED, IYPNTS,

1 MOVE, 'IEEED, NROIS, IQUAD)

$\therefore$

130 CONTINUE

c

return

end

SUBPOUTINE EILESU ( RWC, IXPNTS, XMOVE, XFEED, IYPNTS, 1 YMOVE, YEEED, NROIS, IQUAD )

$\therefore$

$\therefore$ THIS EOUTINE GETS THE SETUP INECRMATION EROM A EIIE

$\therefore$

$\because$ READ THE SETUP INEO. EROM AN IIIPUT EIIE

(

FIIE

BYTE RWC ! CHARACTER TO INDICATE READ OR WRITE ( $R$ OE $i)$ TS

BYTE FILENA ( 40 )

IE (RWC.EQ. 'R') COTO 76

IE (PINC.EQ. 'A') WOTO 126

WRITE $(5,10)$ RWC

iu FOPIAT (' EILESU - INALID REAL/WRITE CHARACTER = ',, 1 ) RETUPN 
$76 \quad \mathrm{NRTTE}(5,4124)$

4124 GORMAT ('OUITER. NAME OE ETLE CONTAIUING BETUP DATE ? ') READ $(5,4125)$ INCEN, EIIENA

4125 EORMAT $(2,40 A 1)$

IF (NCEN.EQ.0) GOTO 76

EILENA $(N C E N+1)=0$

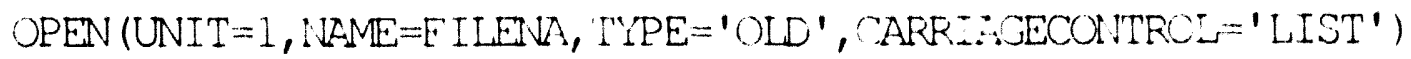

c

$\operatorname{READ}(1,642)$ IXPNTS

$\operatorname{READ}(1,622) \quad \mathrm{MDVE}$

$\operatorname{READ}(1,632)$ VEEED

READ $(1,652)$ TDIR

SEAD $(1,692)$ :ENTS

READ (1,072) ANDVE

PEAD $(1,582)$ :TEED

$C \quad \operatorname{READ}(1,5102)$ VDIR

$\operatorname{READ}(1,6123)$ nrois

$\operatorname{READ}(1,6130)$ IQUAD

CLOSE (UNIT $=1$ )

C

RETURN

6

$\because \quad \therefore$ RITE THE SETUP INFO. TO THE FIIE

$i$.

L $\angle 6$ NRITE $(5,1<4)$

124 EORMAT (' ENTER FILEIAME DOR SAVING SETUE DATA "' READ $(5,125)$ NCEN, EILENA

125 EORMAT (Q, 40A.1)

IE (NCEN.EQ.O) OOTO LI:

EILENA $(\operatorname{INEN+1)=0}$

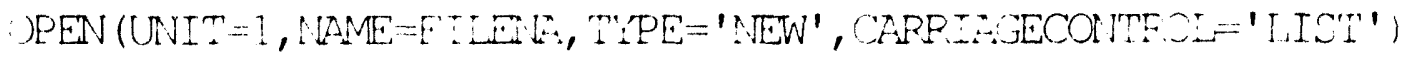

$\operatorname{NRITE}(1,6, \%) \quad$ IXPNTS

MI2 GORMT (I')

WRITE $(1,622)$ YMOVE

222 EORMAT (E:E.O)

WRITE $(1,632) \quad \times E E E I$

i) 32 TORMAT (E15.6) 
C WRITE $(1,652)$ :DIR

C652 FCRMAT (E15.6)

WRITE $(1,692) \quad \because$ PNTS

V92 DORMAT (IT)

WRITE $(1,672) \because$ IOVE

672 EORMAT (F15.6)

WRITE $(1,682)$ :EEED

682 EORMAT (i15.5)

write $(1,6123)$ nrois

6123 format (i6)

WRITE $(1,613 \mathrm{C})$ IQUAD

I30 EORMAT (I3)

CIOSE (UNIT:-)

RETURN

ED 
$\because:=E N A M E: \quad$ SAVDAT.FOR

subroutine savdat ( ixpnts, iypnts, nrois )

this routine gets the data from memory and puts :- in a data $\therefore:$

integer *2 isdata $(4,512$ ) ! data buffer $\mathrm{fz} 1$ line

IRITE $(1,833)$ IXPNTS, IYPNTS, INROIS ! EIRST LI:E OE DATA ETIE

$\because 3:$ EORMAT ('+' $, 19,3 X, 19,3 X, 19)$

CALL IGET ! INITIALIZE "GETPNT" ROUTINE

LOOP TO GET IIL POINTS EEOM UPPER MEMORY

20 CONTINUE

isdir $=-1$ ! scan direction

2

do 305 line $=1$, iypnts

isdir $=$ isdir * -1 ! calculate scan direszion

if (isdir.eq.-1) goto 133 ! get reverse data

forward scan data

do 300 ipnt $=1$, i:pnts

do 202 ir $=1$, nrois

CALL GETPNI ( icp )

isdata $($ ir, 1) = icp

! loop for each regic.. of interest

! GET DATA POINT ( II:CR. TO IEXK)

ontirne

! put data in kisfer array

write $(1,30 i)$ (isdata $(i n, 1), i r=1$, :rois)

$\therefore 1$ cormat $(1 \because, \vdots 3,3 \cdots, i, 3 \because, i 9,3 \because, i 9)$ 


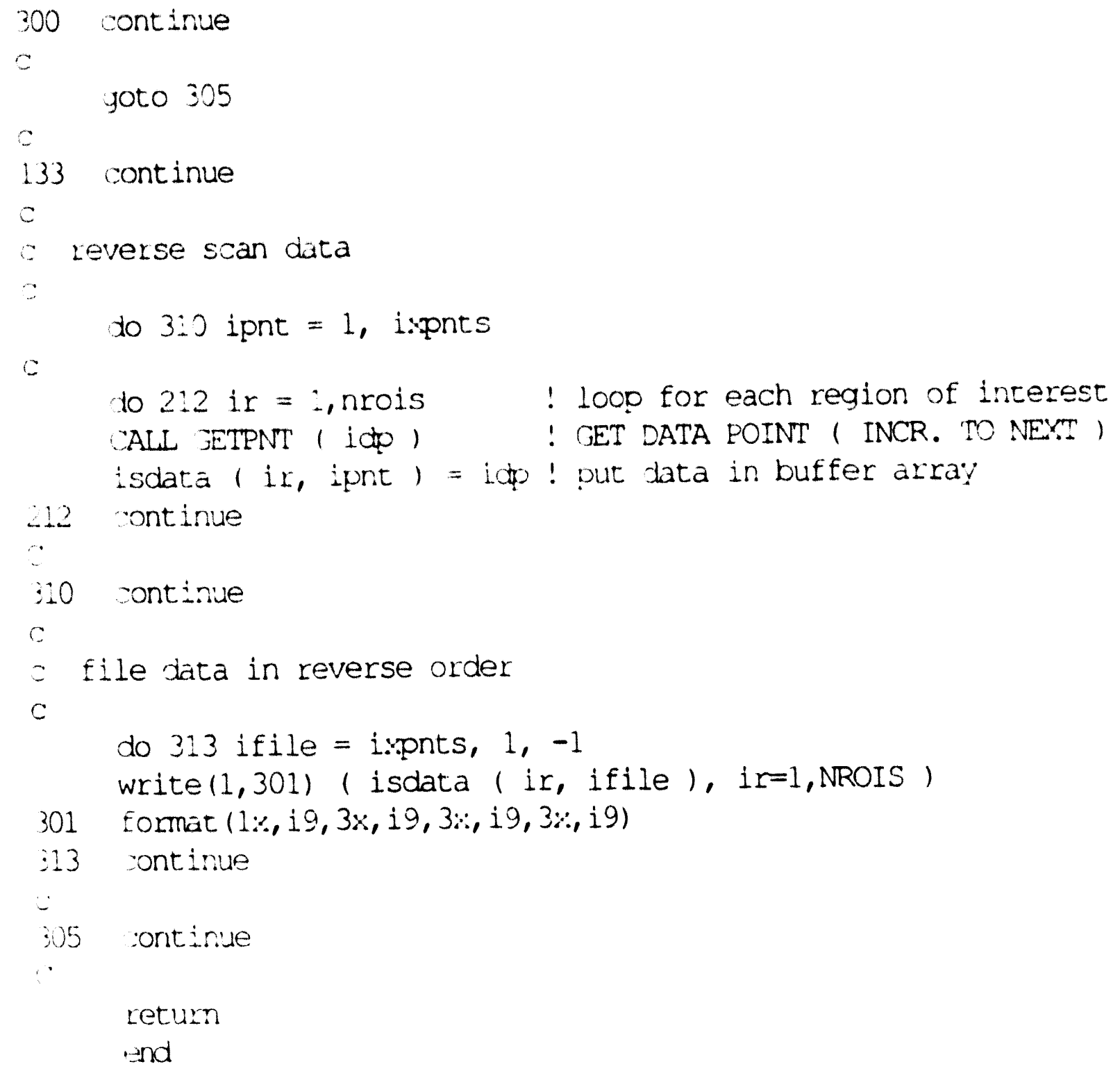


FIIEDEIE: UDXFPO.FOR

SUBROUTME UOXPRG ( IXPNTS, XDIR, MDVE, IFEED,

!

1

IYPNTS, YDIR, YMOVE, YEEED,

UPROG, NOUP)

THIS ROUTIIE CREATES THE UNIDEX III FROGRAM EOR MAKINO THE SC::

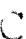

C PERAMETEPS FE CALCULATED FOR THE UNIDEX III PROGRAM

C ECP MOVING TO STARTING POSITIONS AND REMOVIIS BACILAST:

$\rightarrow$

$\therefore$ CEROK - ONOEE PNOXRM AFRAY

c

SYTE CR, :F, :NLL

SYTE UPROS ( 512 )

$\mathrm{R}=13$

$E=10$

NULL $=0$

C

$\because S P M=1 . !$ I OF STEPS PER MICRON OF $\times$ AXIS

$\because S P M=1 . \quad$ ! \# OE STEPS PER MICRON OF Y AXIS

$\zeta$

C XTOVE - THE TOTAL $X$ AXIS MOVE

C. $\because x \because \because$

$\therefore$ TMOVE $=\because S P M *$ YMOVE * FLOAT (IXPNTS) ! TOTAL \# STEPS FCE

$\therefore$ TMOVE $=\because$ TMOVE +1 .

$\therefore$ TMOVE $=\because T M D V *$.DIR

$!+1$ EOR ED STEP

! SET $\because$ MOVE EFECTICN

$\because$ TMOVE $=$ YSEM * YMOVE $*$ YDIR

! SET ? MOVE EFEECTION

‥NEFT PULOE PERIODS EROM SECONOS TO MICROSECONDS

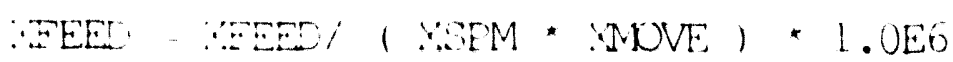

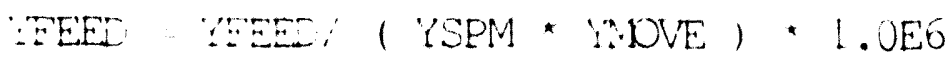


CONSTRUCT THE E:-DIRECTIONRL UNIDEX PFOGE:N

ENCODE $(512,133, \mathrm{UPROG}, \mathrm{ERR}=143)$ IYPNTS, Y.MDVE,

1 XFEED, :TMOVE, YFEED, -XTMOVE, XFEED,

1 YTMOVE, YFEED, CR, LF, NULL

C

133 EORMAT ('G91 G662:=', $56, ' N 1100 \mathrm{M}-01 \mathrm{M}-005200 \mathrm{X}$,

$1 \quad F 15.0, ' E=1, F 15.0,{ }^{\prime} * G 672 Y^{\prime}, F 15.0, ' E=1, E 15.0$,

$1 \quad$ NO M-0:M-00 E200 X',E15.0, 'E=', $5: 5.0$,

$1 \quad$ 'NO G672 $Y ', E 15.0, ' E=1, E 15.0,{ }^{\prime} N>1: 00$ *

1 D100 M- : M-00:22\%, $3 A 1)$

SOTO 150

143 STOP ' ERROF - "FSCAI", CREATING UNIDEX PPOGRAI'

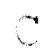

:50 IPO=0! POINTER TO POSITION EOR CHARACTE? PLACEMENT

(

( REMOVE ALL BLAIRS AND DECIMAL POINTS EROM 'NIDE? PROGRAM

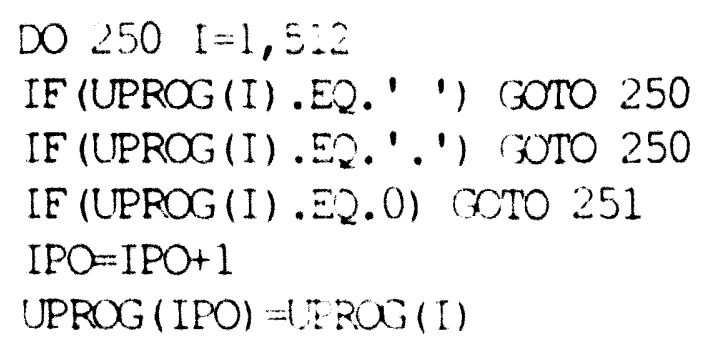

.50 CONTTNUE

. 1 ONTINUE

WUPliPO : * OF CIIR. IN PROGRAM STRII:

WRITE $(5,155)$ :KUT

.55 FORMAT (' PROGTAM LEIGTH $=1, \pm 6$ )

WRITE $(5,160)$ (UPROG (I) , $I=1, N C U P)$

.5O FORMAT $(1 K, 7,2.1)$

RETURN

AD 
FIIEIAME: GRINEO.FOR

subroutine grinfo ( filena, ixpnts, iypnts, nrois )

byte filena (40)

70 write $(5,71)$

71 format (' Enter filename for data (press return to abort )') read $(5,72)$ nc, (Eilena ( $i), i=1,40)$

2 format $(q, 40 a 1)$

filena $(n c+1)=0$

iE (no.el.o) seturn

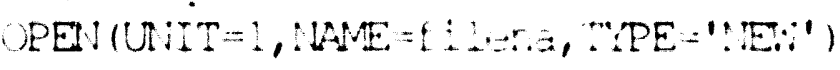

(1) $\operatorname{ARITE}(5,191)$

$19 ?$ FORMAT (' ENTER \# X POI:.WS')

PEAD $(5,192)$ IXPNTS

192 EORMAT (2I6)

WRITE $(5,211)$

212 EORMAT (' ENTER \# Y POIITS')

READ $(5,212)$ IYPNTS

212 EORMAT (2I5)

NRITE $(5,231)$

$\therefore$ CORMAT (' ENTER \# ROIS')

READ $(5,232)$ NROIS

2 FORMAT (2I6)

i

WRITE $(5,240)$ LXENTS, IYENTS, INPOIS

a MORMAT( $\#$ \# POINTS $=1,16,1^{\prime}$ \# Y POINTS $=1,16,1^{\prime}$ \# ROIS $=$ $1,-41$

L9 TRITE $(5,241)$

29 OORMAT(' CORPECT? $" 1)$

PEAD $(5,242)$ ANS

$\therefore$ DOPMAT (A1)

IE (ANS.EQ. 'W') SOTO 19 ,

IE (ANS.AE. 'Y') COTO 299

return

and 
FILENME: PREPAR.EOR

SUBROUTINE PREPAR

C

C THIS ROUTINE PEOMPTS THE USER TO SET OR CHECK THE ORIGIN AII ROIS

C

233 WRITE $(5,234)$

234 EORMAT (' HAS THE ORIGIN BEEN SET ( $Y=$ CONTINUE,

I $N=$ STOP ) ? ')

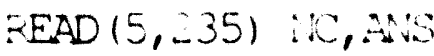

$\therefore 35$ EORMAT (Q, A1)

IF (NC.EQ.0) OOTO 233

IE (ANS.EQ. 'N') STOP

IE (ANS.NE.' $Y$ ') GOTO 233

C

243 VRTTE $(5,244)$

244 EORMAT(' NOTE: IF THE MCA IS AQUIRING WHEN

1 AN ROI IS DEFINED, IT MUST BE ', ,

1' STOPED AND RESTARTED FOR IT TO

1 RECOGNIZE THE ROI ( PRESS ', /,

1' THE "STOP" BUTTON AND

1 THEN THE "ACQUIRE" BUTTON ). ')

245 IRTTE $(5,246)$

246 FORMAT('OHAVE THE ROI (S) BEEN SET ( $Y=$ CONTINIE, $N=$ STCE)

? 1)

$\operatorname{READ}(5,247)$ :N, NNS

$\therefore 47$ FORMAT $(2, A 1)$

IE (NC.EQ.O) SOTO 245

IF (ANS.EQ.' '?') STOP

IF (ANS.NE. ' "') XTO 245

PETUNI

$\because N$ 


\section{ARPENDIX D EXAMPLE UNIDEX III PBOGRAM}

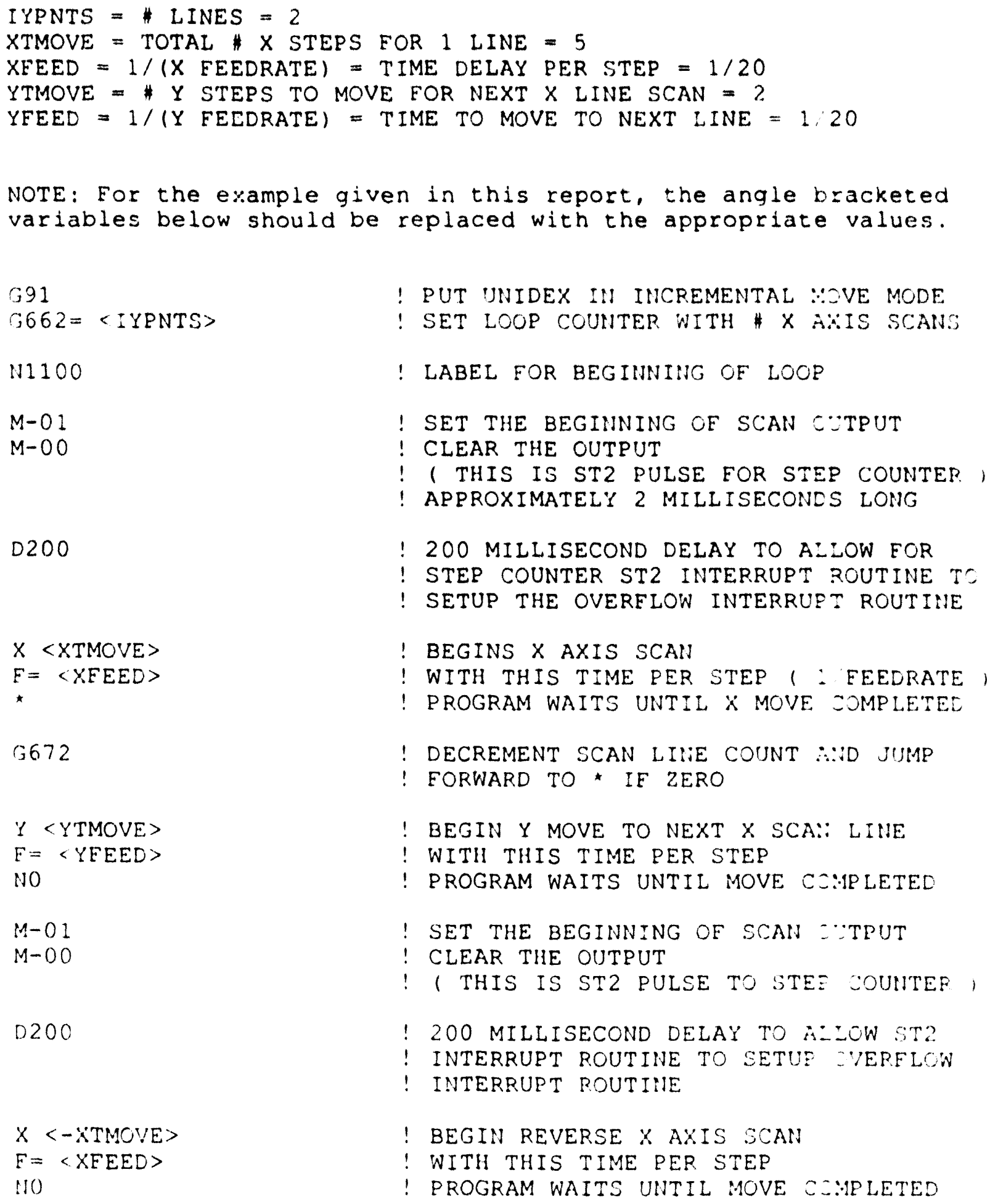

G91

C662 $=$ 〈IYPNTS>

N1100

$M-01$

$M-00$

D200

$X$ <XTMOVE>

$F=\langle X F E E D\rangle$

9672

$Y$ <TMOVE>

$F=\langle Y F E E D\rangle$

NO

$M-01$

$M-0 O$

D200

$x<-X T M O V E\rangle$

$F=\langle X F E E D\rangle$

(1)

! PUT UNIDEX III IMCREMENTAL OOVE MODE

! SET LOOP COUNTER WITH \# $X$ AXIS SCANS

! LABEL FOR BEGIUNING OF LOOP

SET THE BEGIMNING OF SCAN CUTPUT

! CLEAR THE OUTPUT

( THIS IS ST2 PULSE EOR STEP COUNTER )

! APPROXIMATELY 2 MILLISECONOS LONG

200 MILLISECOND DELAY TO ALLOW FOR

! STEP COUNTER ST2 INTERRUPT ROUTINE TO

! SETUP THE OVERFLOW INTERRUPT ROUTINE

BEGINS $X$ AXIS SCAN

! WITH THIS TIME PER STEP (: EEEDRATE )

PROGRAM WAITS UNTIL $X$ MOVE COMPLETES

DECREMENT SCAN LINE COUNT $\therefore$ :UD JUMP

FORWARD TO * IF ZERO

BEGIN Y MOVE TO NEXT X SCA: LINE

WITH THIS TIME PER STEP

PROGRAM WAITS UNTIL MOVE CO:IPLETED

SET THE BEGINNING OF SCAN ZTPUT

CLEAR THE OUTPUT

( THIS IS ST2 PULSE TO STEE COUMTEF,

200 MILLISECOND DELAY TO AELOW ST?

INTERRUPT ROUTINE TO SETUE -VERELON

INTERRUPT ROUTIIIE

BEGIN REVERSE $X$ AXIS SCAN

WITH THIS TIME PER STEP

PROGRAM WAITS UNTIL MOVE COYPLETED 


G672
$Y<Y$ TMOVE>
$E=<Y E E E D>$
$N>1100$
$*$
$D 100$
$M-01$
$M-00$
$\because 2$

! DECREMENT LINE SCAN COUNT AND JUMP

! END OE PROGRAM 
Distribution:

A.K. Lce/DOE.OSA1,9731.MS-8175(2)

S.G. Snow/W.D. Broscy

Y-12 Central Files

9202 File Point 
11
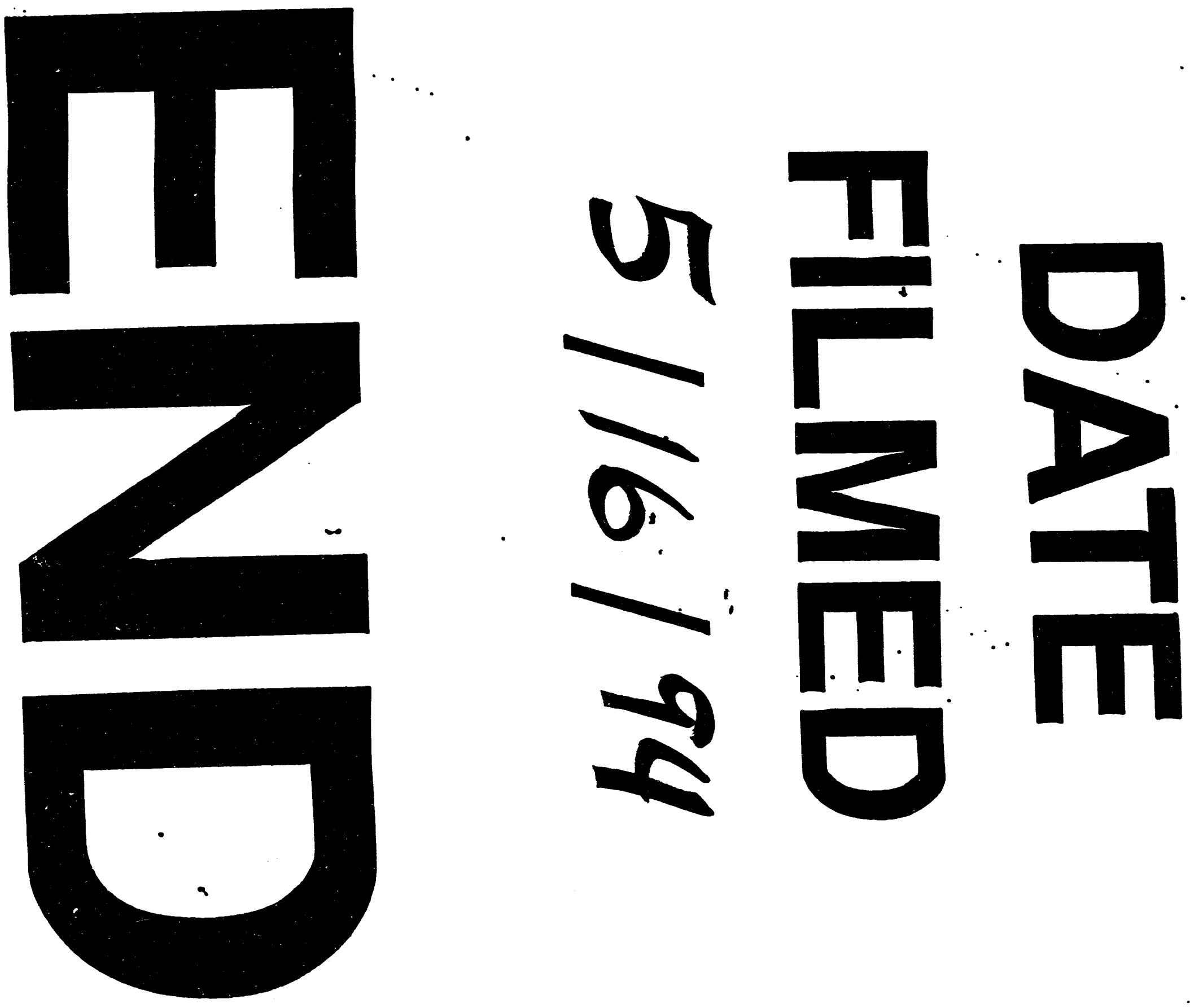


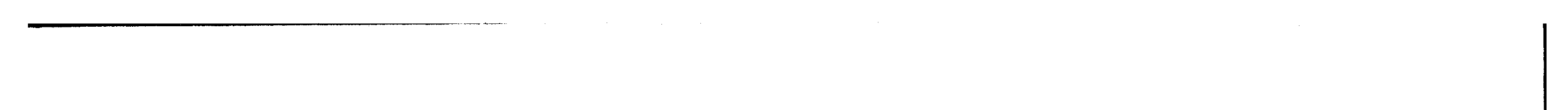

